\begin{abstract}
Title of Thesis:

AN ACTOR PARTNER INTERDEPENDENT ANALYSIS OF THE RELATIONSHIP BETWEEN EVALUATIONS AND AFFECT AND SESSION ATTENDANCE IN GROUPS
\end{abstract}

Russell Alan Jones, Master of Arts, 2011

Thesis directed by: $\quad$ Professor Dennis M. Kivlighan, Jr., Ph.D.

Department of Counseling and Personnel Services

This study examined the relationship between group members' session evaluations and post-session affects and group members' attendance in interpersonal growth groups using the session evaluation questionnaire (SEQ; Stiles, 1980). To test the effect of the SEQ scores on attendance in the following session, the Actor-Partner Interdependence Model (APIM) was used (Kashy \& Kenny, 2000). Results from the APIM analysis were used to examine the effects of session evaluation and postsession mood data on attendance. Group member's positivity was related to group member's attendance, and other group members' smoothness and arousal were related to other group members' attendance. There were no significant relationships between group member's mood or evaluation and other group members' attendance. Other group members' depth, smoothness, and arousal were related to group member's attendance. These findings suggest that not only do other group members influence each other, but they also influence group members. 


\title{
AN ACTOR PARTNER INTERDEPENDENT ANALYSIS OF THE RELATIONSHIP BETWEEN EVALUATIONS AND AFFECT AND SESSION ATTENDANCE IN GROUPS
}

\author{
by \\ Russell Alan Jones \\ Thesis submitted to the Faculty of the Graduate School of the \\ University of Maryland, College Park in partial fulfillment \\ of the requirements for the degree of \\ Master of Arts \\ 2011
}

Advisory Committee:

Professor Dennis M. Kivlighan, Jr., Chair

Professor Karen M. O'Brien

Professor Matthew J. Miller 
CCopyright by

Russell Alan Jones

2011 
Table of Contents

Table of Contents...........................................................

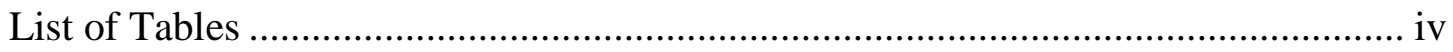

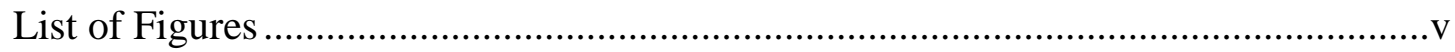

Chapter 1: Introduction to the Problem......................................

Chapter 2: Review of the Literature..........................................4

Pretherapy Characteristics and Attendance and Dropout....................4

In-Group Processes and Attendance and Dropouts....................... 11

Cohesion and Attendance................................................... 11

Alliance and Attendance................................................ 15

Group Climate and Attendance.................................................. 16

Affect and Attendance................................................16

Pretherapy Factors and In-Group Processes............................17

Limitations of In-Group Individual Processes............................18

Actor and Partner Effects.............................................20

The Role of Evaluation and Affect in decisions about Session Attendance...22

Measuring Attendance............................................24

Chapter 3: Statement of the Problem............................................25

Summary and Purpose................................................25

Explanation of Terms...............................................26

Hypotheses......................................................27

Chapter 4: Method.............................................................. 30

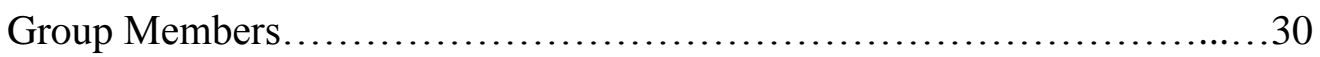

Group Leaders.................................................... 30

Groups.......................................................... 31

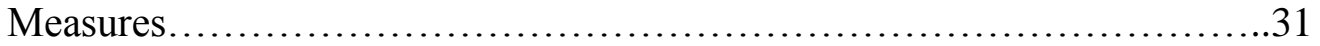

Session Evaluation Questionnaire.............................31

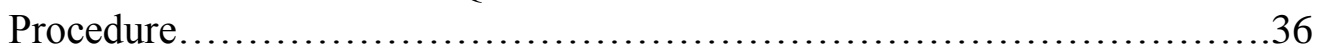

Actor-Partner Interdependence Model............................36

Chapter 5: Results...................................................... 38

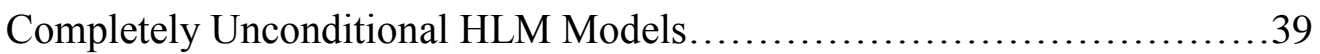

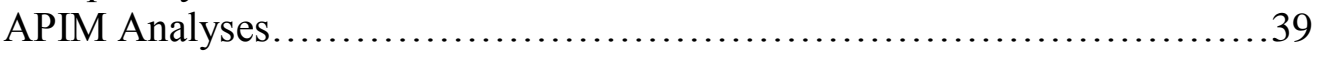

Group Member Actor Effects...........................................44

Group Member Partner Effects.......................................45

Other Group Member Actor Effects......................................45

Other Group Member Partner Effects...................................46 
Chapter 6: Discussion........................................................... 48

Group Member Actor Hypothesis........................................ 49

Group Member Partner Hypotheses ..................................55

Other Group Member Actor Hypotheses.................................56

Other Group Member Partner Hypotheses................................58

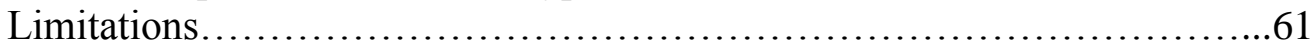

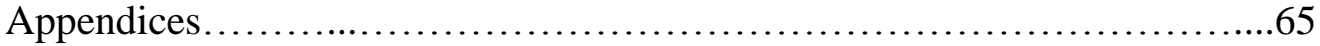

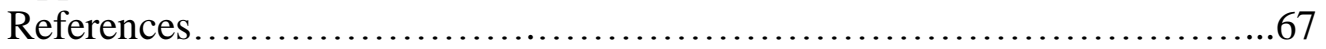




\section{List of Tables}

Table 1. Correlations..................................................... 38

Table 2. Group members and other group members mood and cognition and

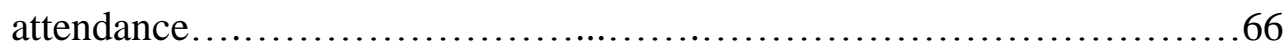




\section{List of Figures}

Figure 1. APIM with group member actor hypothesis........................27

Figure 2. APIM with group member partner hypothesis.........................28

Figure 3. APIM with other group member actor hypothesis......................29

Figure 4. APIM with other group member partner hypothesis...................29

Figure 5. Traditional APIM.................................................. 37

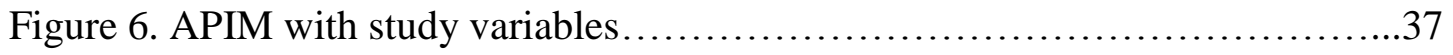

Figure 7. APIM with group member actor results.............................44

Figure 8. APIM with group member partner results..........................45

Figure 9. APIM with other group member actor results........................46

Figure 10. APIM with other group member partner results.....................47 
Introduction to the Problem

The phenomenon of poor attendance in groups is important to study because it is a major problem affecting both the non-attending member and the group processes for the attending members. According to Yalom (1995), poor attendance is a ubiquitous problem in group therapy, because it is a common occurrence regardless of group therapy setting/location, number of group sessions, or open/closed group status. Poor attendance also appears to be a precursor of attrition. Yalom (1995) conducted a search of research studies that had, as a part of their study, the attrition rates in various group therapy settings. Included in this study were groups located in university outpatient clinics (Klein \& Carroll, 1986; McCallum \& Piper, 1990; McCallum, Piper, \& Joyce, 1992), VA outpatient clinics (Rosenzweig \& Folman, 1974), and private practice (Weiner, 1984; Stone \& Rutan, 1984; Christiansen, Valbak, \& Weeke, 1991). These groups had group therapy attrition ranges from 17 to 57 percent. These groups also ranged in the number of total sessions with one group having eight sessions (McCallum, Piper, \& Joyce, 1992) and one group having 16 sessions (Rosenzweig \& Folman, 1974). Yet, the majority of the groups had 12 sessions. Lastly, the groups ranged in length and type of groups with some being open-ended (Klein \& Carroll, 1986; Rosenzweig \& Folman, 1974), one being closed group for people dealing with bereavement (McCallum \& Piper, 1990), one being a short-term eight session group (McCallum, Piper, \& Joyce, 1992), and three analytic groups (Weiner, 1984; Stone \& Rutan, 1984; Christiansen, Valbak, \& Weeke, 1991). From these studies, it is evident that high group therapy dropout rates are prevalent in many different types of groups, regardless of group setting, location of group therapy, or duration of sessions. 
According to Yalom (1995), another reason why the lack of attendance is a major problem in group therapy is that poor attendance can lead to devastating results for other group members. Poor attendance by group members disrupts group solidarity and can precipitate poor attendance patterns among other group members (Fieldsteel, 1996). Many studies indicate that poor attendance by group members can lead to dropouts and premature termination and according to Yalom (1995), premature termination "is bad for the patient and bad for the group" (p. 221). Stone, Blaze, and Buzzuto (1980) examined attendance issues in a group study. They found that attendance problems early in groups were linearly related to later dropout.

To elaborate further, group member lack of attendance is a problem in group therapy, which can lead to problems with group cohesiveness and can lead to further absences among members (Yalom, 1995). Yuksel et al. (2000) found that regular attendance is indicative of strong group cohesion, and more cohesive groups have been found to have fewer members who drop out. According to Macnair-Semands (2002), group members may be more willing to disclose information when attendance is stable, and they often closely observe the commitment of other group members. Another problem is that tardiness and irregular attendance usually signify resistance to therapy. Irregular attendance may hinder meaningful work for the rest of the group, often leaving other group members feeling insecure, worried, or angry (MacNair \& Corazzini, 1994). In addition, there is often increased reluctance to disclose private information when attendance among group members is unstable because group members do not wish to repeat their disclosures (MacNair \& Corazzini, 1994). From these studies, it is evident that group members who have poor attendance records do not form strong bonds with 
other members, and ultimately are likely to drop out. It is apparent from these studies that attendance is a problem in group therapy; therefore research examining the factors that contribute to attendance problems should be addressed. Due to the fact that attendance and dropout studies are so intertwined, the review of literature incorporated studies that examined poor attendance in groups, dropouts in groups, and premature termination in groups.

It is axiomatic among group theorists and researchers that the group has an effect on the individual (Yalom, 1995). According to Kivlighan (in press), the powerful influence of the other group members is an idea that is central to group therapy. Freud (1922/1959) observed that the group makes the members of the group feel, think and act differently than they would as individuals. Research on social influence indicates the influence that the group has on group member attitudes, thoughts and behaviors (see Forsyth, 2006).

Unfortunately, the research on therapeutic factors has ignored the influence of the other group members on the individual. To date, there are no studies that have examined how the behavior, perceptions or reactions of the other group members in a session affects a members attendance in the following session. The specific goal of the current study was to examine how group member's and the other group members' reactions to a group session influences the member's attendance in the following session. 


\section{Review of the Literature}

\section{Pretherapy Characteristics and Attendance and Dropout}

The major way that attendance and dropout has been studied is by examining pretreatment individual factors related to attendance rates. In an early study, Yalom (1966) examined the first six months of nine therapy groups in a university outpatient clinic and investigated whether patients completed twelve or less sessions. After analyzing the dropouts and their therapists, Yalom came up with nine major reasons individuals drop out of group therapy. These include external factors, group deviancy, problems of intimacy, fear of emotional contagion, inability to share the therapist, complications of concurrent individual and group therapy, early provocateurs, inadequate orientation to therapy, and complications arising from subgrouping. Some of these factors, including external factors, problems with intimacy, and fear of emotional contagion are related to pretherapy issues that clients bring into groups. According to Yalom (1995), external factors, which include external stress can be characterized by "marital discord with impending divorce, impending career or academic failure, disruptive relationships with family members, bereavement, and severe physical disease" (p. 226). Problems with intimacy can be characterized by withdrawal, maladaptive selfdisclosure, and unrealistic demands for instant intimacy (Yalom, 1995). Finally, fear of emotional contagion is explained as being adversely affected by the problems of others.

For many researchers, the rationale for exploring pretreatment individual characteristics including, but not limited to, external factors, intimacy problems, and emotional fears is to identify potential dropouts before forming therapy groups (McCallum, Piper, Joyce, 1992; MacNair \& Corrazzini, 1994). Yalom (1995) advocates 
the study of early dropouts in order to establish criteria for excluding certain individuals from group therapy, thus helping the participant selection process.

There are several studies that reflect the tendency to examine the relationship between pretreatment characteristics and attendance and dropout (McCallum, Piper, \& Joyce, 1992; MacNair \& Corrazini, 1994; Kelly \& Moos, 1993; Kotkov, 1958; Stone \& Rutan, 1984; Klein \& Carroll, 1986; Connelly et al., 1986). McCallum, Piper, and Joyce (1992) studied 109 patients who were experiencing prolonged grief. These patients were assigned to one of 16 12-week analytically-oriented therapy groups. McCallum and her colleagues found that almost $30.3 \%$ of the sample (or 33 patients) dropped out of group therapy. A dropout was defined as someone who attended at least one group session and terminated prematurely. Of the 33 dropouts, 21 attended between one and four sessions (early dropouts), and 12 attended between five and eight sessions (late dropouts). All patients were given a set of pretherapy measures. These measures included psychological mindedness, demographic characteristics, diagnoses, psychotropic medications, characteristics associated with loss, previous treatments, importance of the target objectives (personalized goals for therapy), and patient and outcome expectations of therapy. The 33 patients who dropped out were found to be less psychologically minded, have greater number of symptoms, and greater intensity of target symptoms than the 76 people who completed treatment.

Macnair and Corrazzini (1994) also examined client factors that influence group therapy dropout. The focus of their study was to identify client variables influencing group behavior. The rationale behind this study is that although group therapy experiences vary with respect to structure, theoretical orientation, and composition, there 
is some limited evidence suggesting that client factors provide the most variance in predicting dropout. At the time of intake, all subjects completed a problem checklist, personal data form, and an information sheet including family, school, and work information. An initial analysis revealed that there were no significant differences between continuers and dropouts on age, gender, or race. MacNair and Corrazzini (1994) found that clients were likely to drop out of group if they presented with an alcohol problem and had numerous somatic complaints at intake. They also found that clients who reported problems with introversion (i.e., difficulty with shyness, friends, socializing, and loneliness) and with hostility/conflict (i.e., general fighting, fights with partner, and roommate difficulties) at time of intake were likely to terminate prematurely. In addition to pretreatment and client factors, Kelly and Moos (2003) also found that dropout status was linked to prior therapy and demographic information. Kelly and Moos (2003) examined the prevalence of dropouts from 12-step self help groups after a year of treatment. They found that variables that predicted dropout included being of non-African American background, having lower motivational readiness to reduce or stop substance use behavior, less belief in the disease model of addiction, a lower degree of prior involvement with 12-step fellowships, less attendance at religious services, and less social involvement.

Kotkov (1958) examined the differences between dropouts and continuers in Veterans Administration outpatient groups. Using the initial interview with these patients, Kotkov found that compared to patients who remained in therapy, eventual dropouts tended to be more spontaneous and hostile, demonstrated more somatization 
including headaches, insomnia, and restlessness, appeared less motivated for treatment, and were less psychologically minded.

Prior individual therapy also seems to affect attendance and dropout from groups. Stone and Rutan (1984) examined a total of 147 patients who were between the ages of 25 and 55. Stone and Rutan examined their attendance in 2-ongoing psychotherapy groups, each conducted by one of the authors. The first therapist in one group treated 113 patients, while another therapist (second therapist) in another group treated 34 patients. Some of these patients has been seen concurrently in individual therapy by one of the two therapists prior to joining the group. The dropout rate in the 1st year for patients was similar for both therapists, but results were mixed when new members were added to groups. To explain, the first therapist had a significant decrease in dropouts when patients were added to ongoing cohesive groups, while the second therapist had a continuation of the same level of attendance when members were added. An explanation for these mixed results was that the therapist differed in group preparation, and groups differed in patient availability. In addition to inconsistencies in dropouts when members were added to groups, the authors found that the time of dropout differed between the two therapists: The first had patients drop out in a consistent fashion, while the second had most patients stop therapy in the first 6 months. Also the fist therapy added new members in a consistent fashion, while the second therapist waited a year before adding new members. Stone and Rutan (1984) believe the technique of the second therapist of adding new members after a year may have caused increased expectations and stress to the remaining group members. Ultimately, the authors found that individual therapy prior to 
entering group psychotherapy and concurrent individual therapy contributed to patients remaining in group psychotherapy.

Klein and Carroll (1986) studied relationship between patient sociodemographic characteristics and attendance patterns in group therapy, by examining the records of 719 outpatients referred for group therapy over a 3-yr period. The authors had data that indicated that therapy was primarily provided for moderately to severely disturbed patients; mostly single White females from working and middle-class backgrounds; university students; and unemployed, poorly educated minority group members during this 3-year period. Klein and Carroll (1986) found that $41 \%$ of the subjects initially referred never attended a therapy group and among those who did begin group therapy, dropouts occurred most frequently during early sessions. In addition to this, over half of the treated patients were seen for a total of 12 sessions or less. The authors conclude that a high dropout rate of people occurs with people of lower socioeconomic class.

Connelly, Piper, DeCarufel, \& Debbane, (1986) examined the relationships between pretherapy patient characteristics, early therapy experiences, and dropping out in 66 outpatients with neurotic and mild-to-moderate characterological disorders. Connelly and his colleagues found that $33 \%$ of the patients dropped out during the first 6 months of therapy. These dropouts tended to have a primary diagnosis of personality disorder, no previous experiences with therapy, less positive levels of interpersonal functioning, and more negative expectations about climate and mood in therapy. The dropouts were also less committed to their groups and had less perceived compatibility among the patients. Using studies that have examined pretherapy factors influencing dropouts, Yalom (1995) summarized the pretherapy characteristics of patients who have low attendance in 
groups and/or dropout of groups. He stated that these individuals are likely to have the following characteristics: lower psychological-mindedness, high denial, high somatization, lower motivation, less likeability, lower socio-economic status, lower social effectiveness, and lower IQ.

Examining pretherapy individual factors that affect group attendance has limitations. A major limitation of the group literature examining only pretherapy characteristics influencing attendance is the small amount of variance accounted for in these studies (Kelly and Moos, 2003; MacNair-Semands, 2002; McCallum, Piper, \& Joyce, 1992). For example, Kelly and Moos (2003) were only able to explain approximately $7 \%$ of the variance in dropout status at 1 year. This means that $93 \%$ of the variance of dropouts can be explained by other factors. As noted earlier, McCallum et al. (1992) despite finding that dropouts were less psychologically minded, have greater symptomatology, and greater intensity of target symptoms than continuers remainers; they suggested that in general the pretherapy variables have failed to identify dropouts. Macnair-Semands (2002) showed that that social phobia/inhibition accounted for $6.9 \%$ of the variance, while angry hostility accounted for $7.2 \%$ of the variance. She indicated that "researchers must search for additional means of predicting member success in group therapy that do not rely solely on client reports of personal characteristics. In attempting to predict attendance patterns, the amount of variance directly attributable to client characteristics alone is small. The amount of variance accounted for is an important limitation of this study, and consequently one must recognize that there are relatively few client-only factors that will be consistently predictive of group behaviors and perceptions about group" (p. 226). Another problem 
in the pretherapy literature is inconsistent findings. One issue is the amount of interpersonal distress clients' exhibit prior to entering groups. One the one hand, there are authors in the group therapy literature have speculated that high interpersonal distress, measured prior to the group beginning, is desirable for group therapy participation (Frances, Clarkin, \& Perry, 1984). Yet, other authors concluded that high interpersonal distress is associated with poor attendance and dropping out (Roback \& Smith, 1987). In addition to this, there is conflicting information about how prior individual therapy affects group therapy attendance. There are some studies that have found that individual therapy prior to a group improves the outcome of the individual in the group. MacNair and Corrazzini (1994) found that the experiences of both individual therapy prior to entering group counseling and concurrent individual therapy have also contributed to clients' remaining in group psychotherapy. Stone and Rutan (1984) found that clients with either a prior history of individual therapy or concurrent individual and group therapy tended to remain in a dynamically oriented treatment group. Similarly, Connelly et al. (1986) found that dropouts were less likely to have previous therapy experience. On the other hand, Kotkov (1955) found that prior individual therapy was a deterrent to attendance in group psychotherapy. There are also several studies that indicate that termination rates seem to increase as a result of client transfer from individual to group therapy (Kotkov, 1955; Yalom, 1966).

Given the small amount of variance found in attendance studies that use pretherapy individual characteristics, and the inconsistent findings including the effects of prior individual therapy on attendance, researchers began to investigate other factors affecting attendance problems in groups. 


\section{In-Group Processes and Attendance and Dropouts}

As noted, previous research on dropping out from group therapy has emphasized identifying differences between dropouts and remainers before treatment begins. Unfortunately, the search for pretherapy characteristics associated with dropping out has been disappointing and inconsistent. In addition, as seen in studies by Kelly and Moos (1993), MacNair-Semands (2002), and McCallum et al. (1992) statistically significant associations of these studies are often small in magnitude. If pretreatment individual characteristics do not account for enough variance and are therefore not good predictors of attendance problems, researchers need to examine other predictors. In-group individual processes can be an alternative way to predict attendance problems in groups. Rather than differing on pretherapy individual variables, dropouts may be differentiated from continuers in their response to treatment (McCallum et al., 2002). When examining in-group individual processes and individuals responses to treatment, it is important to consider how certain in-group individual factors influence attendance, including individual factors, leader factors, and group factors. Thus, in-group individual factors related to the group including group cohesion and climate, leader factors including individual alliance with the therapist, and individual factors including the affect of group members can all influence attendance and dropout (McCallum et al., 2002).

Cohesion and Attendance. According to McCallum et al. (2002), cohesion can be defined as the "relational bonds among group members, the therapist, and the group itself" (p. 244). There are several studies that examine cohesion among groups and how cohesion is related to the attendance of group members (Falloon, 1981; McCallum et al., 2002; Ogrodniczuk et al., 2006; Piper, Jones, Lacroix, Marrache, \& Richardsen, 1984; 
Piper, Marrache, Lacroix, Richardsen, \& Jones, 1983). Researchers have argued that regular attendance is a marker of group cohesion, and more cohesive groups have been found to have fewer members who drop out (Falloon, 1981). Falloon examined 51 psychiatric outpatients with specific interpersonal skills deficits. He had subjects complete 10 sessions of behavioral group therapy after being randomly assigned to 9 small groups employing either (a) role rehearsal and modeling or (b) guided discussion. These subjects self-rated their attraction toward the group as a whole and toward male and female co-leaders after each session. Falloon found that higher levels of attraction were obtained in role rehearsal groups than in the guided discussion groups. These higher levels of attraction were associated with improved self-esteem and a reduction of specific fears at the end of treatment. He also found that dropouts showed less attraction and tended to leave the groups at critical stages in their development. These findings suggest that greater attention to specific interpersonal variables may enhance the effectiveness of group therapies, including attendance.

McCallum, Piper, Ogrodniczuk, and Joyce (2002) investigated relationships between early group process and dropping out from a randomized clinical trial of two forms of time-limited group psychotherapy for complicated grief, interpretive and supportive. They investigated differences in the therapy process of dropouts and continuers. The process battery consisted of measures of cohesion, alliance, group climate, and affect. They found that after the 1 st therapy session, imminent dropouts reported experiencing less positive feelings than continuers. In addition, therapists' ratings of cohesion to the patients were significantly lower for the dropouts than for continuers. 
Ogrodniczuk, Piper, and Joyce (2006) examined the role of interpersonal distress as a predictor of session attendance for patients with personality disorders $(n=72)$ in two different forms of group psychotherapy, interpretive therapy and supportive therapy. They also wanted to examine whether patients' cohesion to their therapy group mediated the effect of interpersonal distress on attendance. The findings indicated that there was minimal association between interpersonal distress and attendance in interpretive therapy $[r(32)=-.11, p>.50 ; R 2=.01]$. However, there was a strong association between interpersonal distress and attendance in supportive therapy $[r(36)=.43, p<.01 ; R 2=$ .19]. The authors also found that lower interpersonal distress was associated with poorer attendance in supportive therapy. Conversely, higher distress was found to be associated with better attendance. The authors concluded that patients with low interpersonal distress in supportive therapy attended significantly fewer sessions than patients with low interpersonal distress in interpretive therapy.

Ogrodniczuk et al. (2006) also found that interpersonal distress was directly and significantly associated with cohesion to the group, $F(1,37)=8.07, p<.01, R 2=.18$. This suggested that cohesion to the group could be tested as a mediator of the effect of interpersonal distress on attendance. The authors also found a direct and significant association between cohesion to the group and session attendance $[t(35)=2.50, p<.05]$. From there, they calculated the percentage of the effect of interpersonal distress on attendance that is accounted for by cohesion to the group and found that cohesion to the group accounted for $64.6 \%$ of the effect of interpersonal distress. Thus, the mediation provided by cohesion to the group accounted for nearly two-thirds of the direct effect of interpersonal distress on session attendance in supportive group psychotherapy. 
Piper, Marrache, Lacroix, Richardsen, and Jones, (1983) surveyed 45 participants from 9 experientially based learning groups to collect behavioral data concerning cohesion. The author conducted factor analyses of the self-report data, which generated 3 sets of factors that dealt with the participant's perception of the other participants, the leader, and the group as a whole. These factors were (1) mutual stimulation and effect provided by the group, (2) commitment to the group, and (3) compatibility of the group. Piper et al. (1983) found that the factor concerned with the participant's commitment to the group was significantly related to remaining in the group and physical distance to others but not to perceptions of learning. From these studies, it is understood that patients with strong bonds to the group and its members are more likely to attend sessions and remain, whereas patients with weak bonds are more likely to drop out.

In a subsequent study, Piper, Jones, Lacroix, Marrache, and Richardson (1984) investigated the effect of pregroup interactions on bonding in small groups in a study that varied conditions relating to the people with whom 45 clients interacted prior to beginning a small learning group experience. Three conditions were established: participant-bonded, leader-bonded, and other-bonded. The rates of attending and remaining varied according to with whom patients interacted prior to the onset of the group. For example, the best record of group members attending group and remaining in the group was achieved in the participant-bonded condition. The lowest rates of attending and remaining were obtained in the leader-bonded condition. Piper and his colleagues found that preliminary leader-member interactions are relatively ineffective for the purpose of retaining members early in the life of a group. Also, pregroup interactions were unrelated to evaluations of participant learning. The authors concluded 
that perceived personal compatibility that arises from preliminary peer interactions may help a group retain membership but does not necessarily assure learning or therapeutic change. However, it should be noted there seems to be no examination in any of these studies of the influence of other group members on an individual's attendance.

Alliance and Attendance. According to McCallum et al. (2002), alliance refers to the "collaboration between patients and therapist". Bordin (1979) explains alliance a bit further. He posits that alliance consists of three components: (a) the therapeutic bond (the mutual liking, attachment, and trust between the client and therapist), (b) agreement on tasks (activities that the participants engage in during the session, e.g., cognitive restructuring), and (c) agreement on goals (areas targeted for change, e.g., psychologically and physically aggressive behaviors). Alliance has been primarily investigated for its role in patients' response to individual therapy (Piper et al., 1999). Alliance has also been investigated with group therapy (Budman et al., 1989; Marziali, Munroe-Blum, \& McCleary, 1997) but only occasionally as a predictor of dropping out (Brown \& O’Leary, 2000).

Brown and O'Leary (2000) examined the role of the therapeutic alliance between client and therapist on group treatment outcome in 70 husband-to-wife violent couples. The strength of husbands' alliance with the therapist was assessed at Session 1, and was found to be positively associated with treatment outcome, as measured by decreased husband-to-wife mild and severe psychological and physical aggression. The strength of wives' alliance with the therapist was found to be unrelated to treatment outcome. Finally, although the authors found that therapeutic alliance was related to treatment outcome, it was unrelated to treatment completion. Brown and O'Leary (2000) found 
that despite the finding that alliance was significantly correlated with several measures of treatment success (i.e., decreased mild and severe psychological and physical aggression), it was not significantly correlated with treatment completion. Brown \& O'Leary (2000) also found that there were many reasons why couples dropped out of treatment. Further, the relative number of those endorsing alliance-related reasons for dropping out was small, decreasing the likelihood that there would be a significant relationship between alliance and dropout. Thus, the small number of dropouts who cited alliance-related reasons for discontinuing treatment is consistent with a failure to find a relationship between alliance and treatment completion.

Group Climate and Attendance. According to McCallum et al. (2002), group climate refers to the atmosphere in the group in terms of cohesion, resistance, and friction. It reflects the degree to which members are engaged in the process of group therapy (Mackenzie, 1983; Mackenzie \& Tschuschke, 1993). Group climate has been found to be related to remaining in group therapy (Macnair-Semands, 2002).

Affect and Attendance. Affect also seems to be related to attendance in groups. As mentioned, McCallum, Piper, Ogrodniczuk, and Joyce (2002) investigated relationships between early group process and dropping out from a recently completed randomized clinical trial of two forms (interpretive and supportive) of time-limited group psychotherapy for complicated grief. They also investigated differences in the therapy process of dropouts and continuers. As evidenced by data from the very first therapy session, dropouts reported experiencing significantly less positive affect (pleasure, warmth, acceptance, or optimism) than continuers. That difference was consistent with the therapist's perception that the dropouts were less likable, less desirable as friends, and 
less significant group members. Patients who felt positive about the experience stayed; those who did not, left.

In a previous study of complicated grief, affect was again found to predict outcome in interpretive short term groups (McCallum, Piper, \& Morin, 1993). McCallum et al. (1993) examined 5 positive and 5 negative self-rated affect variables (5 positive and 5 negative) of 154 adults ( $72 \%$ women) who participated in 12 of 16 groups involved in a controlled outcome study of psychoanalytically oriented short-term group therapy. Psychodynamic work variables were rated by trained research assistants for each patient. The groups were conducted by 3 experienced therapists for patients who experienced difficulties adapting to personal losses through death, separation, or both. The authors found that patients who had experienced separation were more inhibited in their affective expression, than patients who experienced death. They also found that all patients reported that positive affect increased over time and that there were direct relationships between positive affect and favorable outcome in groups.

Pretherapy Factors and In-Group Processes. Considering the combination of pretherapy factors and in-group processes is another way researchers have studied attendance problems in groups. Ogrodniczuk et al. (2006) examined the effect of age on attending and completing different types of group therapy among psychiatric outpatients, and whether cohesion among group members mediates the effect of age on attendance. In this study the pretherapy demographic factor, age, was considered to affect attendance, as was the in-group process of group cohesion. Ogrodniczuk and his colleagues used a sample consisting of 139 outpatients who began short- term interpretive or supportive group psychotherapy. Ogrodniczuk and his colleagues found significant associations 
between age, session attendance, and termination status were found for patients receiving supportive group therapy. In other words, age was directly related to attending and completing therapy, the older the person the more likely they would complete therapy. In addition to this, the quality of the relationships among patients (i.e., cohesion) was found to mediate the effect of age on attendance. Depending of the type of group therapy offered, younger patients may be at risk for poor treatment adherence.

\section{Limitations of In-Group Individual Processes}

From these studies, it is evident that in-group individual processes are important and a better option than examining only pretherapy individual characteristics. In-group process can explain more information about attendance and there are stronger correlations and more variance accounted for. Yet, there are limitations to this research. A major limitation of examining in-group factors that affect attendance is failing to separate individual and group factors. For example, in the Macnair-Semands (2002) study, social phobia was characterized by shyness, not being assertive, difficulty socializing, difficulty initiating things on my own, and avoiding social activities. These characterizations can fall under both categories of individual preexisting factors and factors as a result of being in a group. To elaborate, an individual in a group setting may have a history of not being assertive, an individual factor, or it a result from being in a group where assertiveness is met with hostility or where there is pressure to conform, which is a group factor.

Another limitation is the way affect has been studied linking it to attendance. The two studies mentioned earlier which examined affect and attendance focused on affective processes of participants through the duration of groups. Researchers in both of these 
studies collected data on participants' affective states through initial interview measures (McCallum et al., 2002) or end-of-session measures (McCallum et al., 1993). Also, in both studies researchers drew conclusions for group outcome (attendance) based on participant's affective states. These conclusions were characterized by predictions of dropouts based on affect. While these are noteworthy studies, my study on affect focused more on how affect, in addition to session evaluation, influences attendance. Specifically, I examined affect by focusing on whether the mood factors of positivity and arousal affect attendance. Another difference is that my study examined attendance from session to session based on the end-of-session affective state of participants. Other studies have examined attendance globally, from the perspective of affect influencing dropouts versus continuers.

In addition to the studies mentioned on affect, from the studies noted that have examined climate, cohesion, and alliance, there seems to be no indication about how other group members affect affects an individual's attendance throughout sessions. Most of this literature fails to factor the influence other group members have on an individual in terms of attendance (Falloon, 1981; McCallum et al., 2002; Piper et al., 1984).Taking into consideration how another person's actions affect an individual is important. 


\section{Actor and Partner Effects}

To date, there are two studies that examine how other group members may affect an individual group member's behavior (Bonito, DeCamp, Coffman, and Fleming, 2006; Miles, Paquin, \& Kivlighan, 2009). By contrast, there are many relational studies that examine how one person is affected by another person in dyadic groups. According to Kenny and Cook (1999), a defining feature of relational research data is that the models used to analyze the data reflect not only the characteristics of the person who provides the score but also the characteristics of the person's partner. The characteristic of the individual, and the effect that they have on an outcome, can be labeled as actor effects, while the characteristics of the individual's partner, and the effect that they have on an outcome, can be labeled as partner effects.

For example, there have been a number of studies examining the partner effects in dyadic groups, such as romantic couples. In examining dynamics between couples, one might explore the relationship between satisfaction and commitment. A simple hypothesis is that partner A's satisfaction in the relationship is related to this partner A's commitment to the relationship. The relationship between a partner A's satisfaction and their commitment to the relationship would be the actor effect. According the actorpartner literature, Partner B's satisfaction in a relationship is also related to a partner A's commitment to the relationship (Kenny \& Cook, 1999). The relationship between a partner B's satisfaction and their commitment to the relationship would be the partner effect.

Although there have been a large number of studies looking at the influence of actor and partner effects, most of this research has been conducted on dyadic groups, 
such as couples (Campbell, Simpson, Kashy, \& Fletcher, 2001; Robins, Caspi, \& Moffitt, 2000), parent-child dyads (Otten, van der Zwaluk, van der Vorst, \& Engels, 2008), and other dyads such as caregiver and patient (Segrin et al., 2005) and friendships (Popp, Laursen, Kerr, Stattin, \& Burk, 2008). As an example, Kenny and Cook (1999) found that the level of jealously a wife feels about her husband may reflect her own insecurity about relationships (actor effects) as well as her husband's tendency to provoke these feelings (partner effects). Also, Murray, Holmes, and Griffin (1996) found that individuals are more satisfied in their relationship when they know that their partners view them in a favorable manner. There are only two studies that have examined partner effects in group settings (Bonito et al., 2006; Miles, Paquin, \& Kivlighan, 2009).

In one of the few studies looking at actor and partner effects in groups, Bonito et al. (2006) examined the effects of interpersonal control and information quantity on participation in small groups. These researchers posited that a person's participation in a group is a function of his or her degree of perceived interpersonal control as well as of that of one's colleagues. They also hypothesized that the coordination of control affects participation to the extent that one has relevant information to contribute and in concert with the perceived control of one's colleagues. Bonito et al. (2006) found that interpersonal control has both actor and partner effects that are related to the extent that members participate in groups. Bonito et al. (2006) demonstrates that an individual's control orientation itself is insufficient to explain participation differences. In other words, participation in groups is also affected by the degree of interpersonal control by one's colleagues. 
Miles, Paquin, and Kivlighan (2009) examined the relationship between the amount and consistency of the intimate behaviors in the group, and individual group member's level of intimate behaviors. Using the Actor-Partner Interdependence Model (APIM; Kenny, Kashy, Manetti, Piero, \& Livi, 2002), they found that a positive relationship between a group's mean level of intimate behaviors, and an individual's intimate behavior. Given these two studies, it seems possible that partner effects can also influence attendance in groups.

\section{The Role of Evaluation and Affect in decisions about Session Attendance}

If an in-group process is going to be examined to see the effects of group members on an individual's behaviors, it is important to determine which in-group process should be examined. Examining session impact, including session evaluation and post-session mood is important.

Examining session impact and mood is an important area in the group theory, yet is has been relatively unexplored by group researchers. However, it has been studied in individual therapy. Impact refers to a session's immediate subjective effects, including clients' evaluations of the session, their assessments of the session's specific character, and their post session affective state (Stiles, 1980). Measures of impact are concerned with "clients' internal reactions to sessions, which, logically, must intervene between in-

session events and the long-term effects of treatment" (p. 175). -From this explanation, impact seems to capture a person's affect and their cognitions about treatment. When examining session quality, clients in individual therapy who returned for subsequent sessions often viewed their sessions as "deep" and "powerful" (Tryon, 1990). 
Another reason to study session impact is that it is linked to treatment outcome both theoretically and clinically. Session impact, involving participants' post session mood or affect and evaluation of the immediate session effects, has been proposed as a link between counseling process and outcome (Mallinckrodt, 1993; Stiles \& Snow, 1984a). Considerable research examining this has been conducted with the Session Evaluation Questionnaire (SEQ; Stiles, 1980). The most recent forms of the SEQ contain subscales assessing session depth, smoothness, positivity, and arousal (Stiles \& Snow, 1984a, 1984b). Depth is a task-oriented dimension related to the session's value and power. Smoothness refers to perceived comfort, safety, and lack of personal distress. Positivity measures post session moods of confidence and happiness, as well as the absence of anger and fear. Arousal refers to feeling active and excited versus feeling quiet and calm. While depth and smoothness are independent dimensions of session evaluation, postivity and arousal are global dimensions of post-session mood (Stiles \& Snow, 1984).

Client and counselor perceptions of depth in a first session may be related to initial engagement and the client's return for a subsequent session (Tryon, 1990), but initial ratings of smoothness may result in client dropout (Nash \& Garske, 1988). Some evidence suggests that deeper and smoother sessions, as rated by therapists, may be related to positive outcome, although the pattern for clients is less certain (Stiles et al. 1988; 1990). Other research suggests that smoothness may be the most salient variable for clients (Friedlander, Thibodeau, \& Ward, 1985).

In examining mood factors in group members, Macnair-Semands (2002) found that angry clients are more likely to be irritable and annoyed at other members, possibly 
leading to a devaluing of the commitment to attend group. She also noted that interpersonal hostility leads group members to push away or reject the hostile member, contributing to that member's low desire to attend group. Sharry and Owens (2000) found that blocks to the group process can be created by mistaken assumptions about group members' anger, a pattern that undoubtedly leads to poor attendance or dropout of the angry client in some instances.

Only a few studies have examined session impact and treatment outcome. Stiles, Shapiro, and Firth-Cozens $(1988 ; 1990)$ found that therapist-rated depth and smoothness were related to client improvement. Clients' session ratings, however, were not related to outcome. More studies need to be done to link session impact to treatment outcome.

It is not surprising that evaluations are prominent in clients' impact ratings (e.g., whether the session seemed good or bad or whether they felt good or bad afterward) (Stiles et al., 1994). The methodological challenge is to assess whether and how clients discriminate among their sessions in more differentiated, descriptive ways (Stiles et al., 1994).

\section{Measuring Attendance}

In addition to examining the partner effects of session impact, it is also important to consider how to calculate attendance rates. All previous research has examined attendance rates by considering the percentage of session attended (Kelly \& Moos, 1993; MacNair \& Corrazini, 1994; McCallum et al., 2002; Macnair-Semands, 2002). While examining attendance rates by the percentage of sessions attended is adequate for most attendance studies, researchers have raised concerns about this method. For one, measuring attendance as percentage of sessions attended does not consider lapses in 
attendance throughout the therapy during certain group sessions. Furthermore, this does not allow for analysis into why a person missed a certain session. A better approach is to examine attendance at the session level. McCallum et al. (2002) stated at the end of her study that "there were no significant associations between dropping out and the variables type of therapy, therapist, or group. However, group was nested within type of therapy and therapist, and nesting effects involving these variables were not investigated. Data analytic techniques such as hierarchical linear modeling could be used to investigate nesting effects in future studies.” (p. 252). Investigating attendance at the session level, as well as the individual examining variance at the session, member and at the group level will yield a better explanation of findings. This is because attendance may change on a session to session basis based on individual and group ratings of session evaluation and post-session mood; the session becomes the primary unit of analysis.

\section{Statement of the Problem}

\section{Summary and Purpose}

Few studies, have examined how the behavior, perceptions, or reactions of other group members affect the behavior, perceptions, or reactions of a group member. This is especially true for the research examining attendance. To date, there are no studies that have examined how the behavior, perceptions or reactions of the other group members in a session affects a members attendance in the following session. Given the dearth of information on this research topic, one goal of the current study was to use Yalom's theoretical writings (1995) and extend the results of Yalom et al. (1967) study to examine how individual and group evaluative and affective processes impact attendance. 
Undoubtedly, group therapists would agree that a group member's experience in the group is a function of his or her own participation in the group and the participation of the other group members. However, few small group studies simultaneously examine both the individual group member and the other group members. The statistical techniques described by Kenny et al. (2002) provide a powerful tool for examining the contributions of both the individual group member and the other group members. Examining both the group member and the other group members simultaneously will be important in advancing our understanding of group counseling and therapy. As more researchers examine both individual and other group member contributions, it will be interesting to see if future studies also find the relative greater importance of the other group members that was found in this study. These factors are important because they may help researchers and clinicians better understand how cognitions and emotions of group members can affect attendance. The specific goal of the current study was to examine how group member's and the other group members' reactions to a group session influences the member's attendance in the following session.

The purpose of this research was to identify relationships between session impact, through administration of the Session Evaluation Questionnaire (SEQ), which examines session evaluation and post-session mood, and attendance, and understand the role of actor and partner effects.

Explanation of Terms. There are several terms that I used in this study. The term group member referred to an individual member of a group. Group member actor effects referred to the relationship between a focal individual's SEQ scores and their attendance in later sessions. Group member partner effects referred to the relationship 
between a focal individual's SEQ scores and the attendance of everyone else in the group (except the focal individual) in later sessions. The term other group members referred to all of the other members of the group except the focal individual group member. Other group members actor effects referred to the relationship between everyone in the group (except the focal individual) SEQ scores and the attendance of everyone in the group (except the focal individual) in later sessions. Other group member partner effects referred to the relationship between everyone in the group (except the focal individual) SEQ scores and the attendance of the focal individual in later sessions.

\section{Hypotheses}

Group Member Actor Hypothesis. The group member actor hypothesis was that there would be a positive relationship between a group member's depth, smoothness, positivity, and arousal scores and a group member's attendance in subsequent sessions, see Figure 1. This hypothesis was based on research conducted by Stiles, Shapiro, and Cozen-Firth (1988), which found that depth and smoothness were related to client improvement and retention.

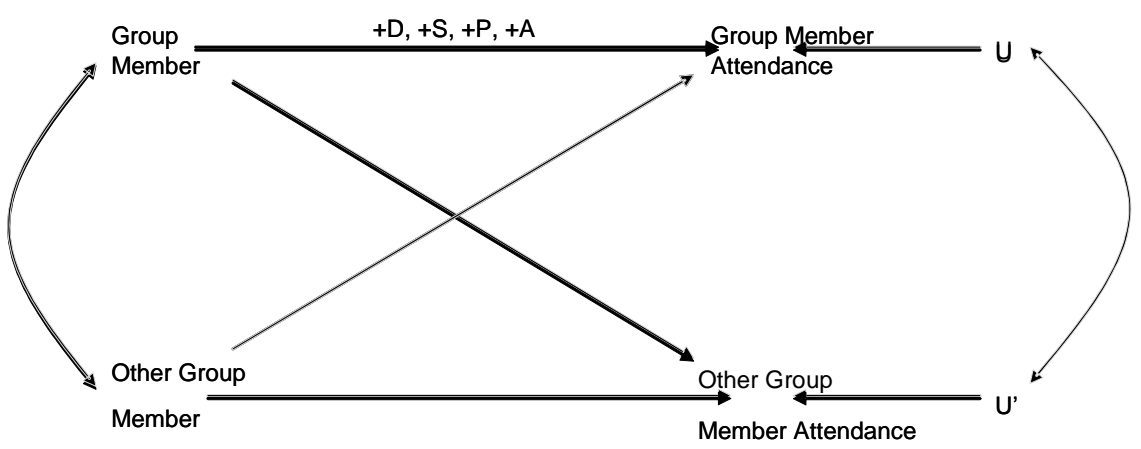

Figure 1. APIM with group member actor hypothesis

Group Member Partner Hypothesis. The group member partner hypothesis was that there would be no relationship between a group member's depth, smoothness, 
positivity, and arousal scores and other group members' attendance in subsequent sessions, see Figure 2. This was based on social influence theory, specific minority influence (Forsyth, 1999). Social influence theory is based on "interpersonal processes that change group members thoughts, feelings, and behaviors" (Forsyth, 1999, p.175). According to Forsyth (1999), much of the direction of social influence flows from the group to the individual, not vice versa. In addition to this, in most group situations 'minority influence' or the influence an individual has on the group, is a less common occurrence.

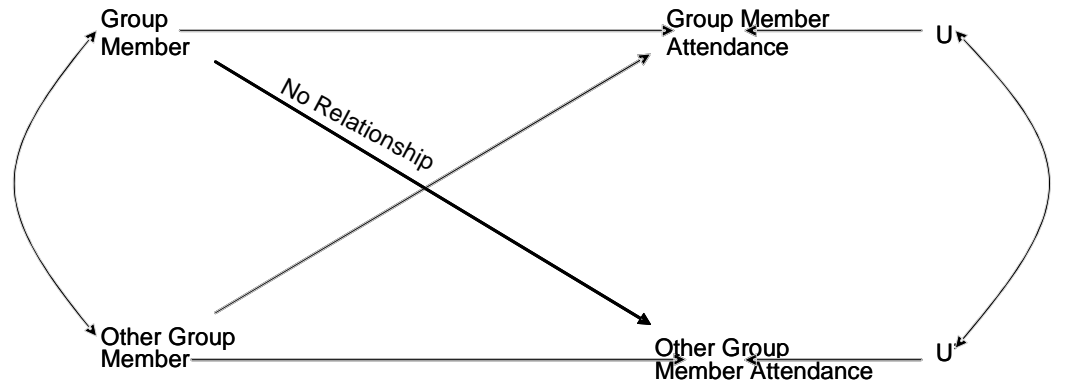

Figure 2. APIM with group member partner hypothesis

Other Group Member Actor Hypothesis. My other group member actor

hypothesis was that there would be a positive relationship between other group members' depth, smoothness, positivity, and arousal scores and the probability that all of the other group members' will attend the subsequent session, see Figure 3. This hypothesis was an extrapolation of the research conducted by Stiles, Shapiro, and Cozen-Firth (1988), which found that depth and smoothness were related to client improvement and retention. 


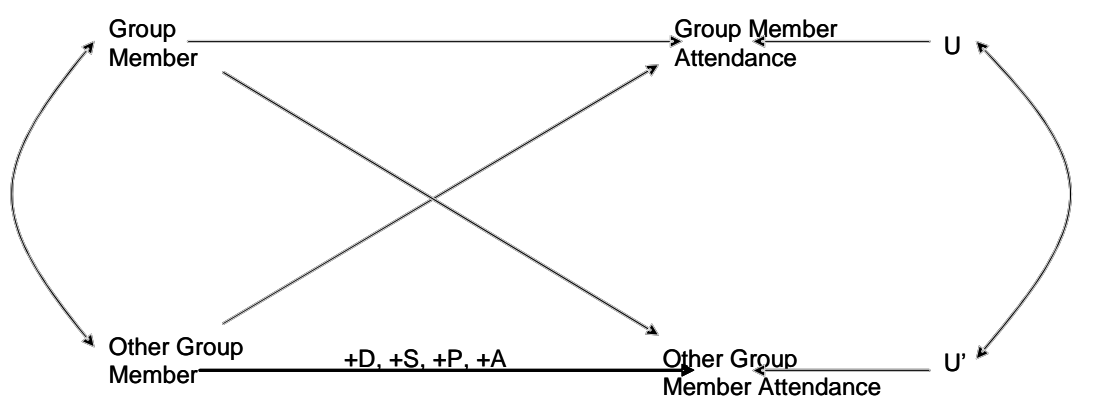

Figure 3. APIM with other group member actor hypothesis

Other Group Member Partner Hypothesis. My other group member partner hypothesis was that there would be a positive relationship between other group members' depth, smoothness, positivity, and arousal scores and a group member's attendance in subsequent sessions, see Figure 4. This was based on previous research on the group's effect on individual group members' behavior (Bonito, DeCamp, Coffman, \& Fleming, 2006).

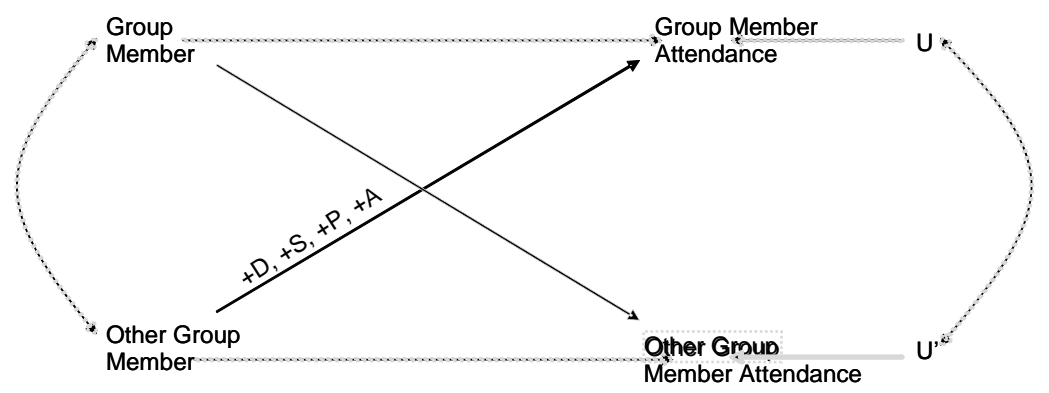

Figure 4. APIM with other group member partner hypothesis 


\section{Method}

\section{Group Members}

The participants were thirty-six students at a large Midwestern university enrolled in an elective class on group processes. Four students were male and 32 students were female, their ages ranged from 19 to 45 years $(M=24.1, S D=6.4)$, and their ethnic backgrounds were 33 white, 1 African American, 1 Asian American, and 1 Native American. The participants' college majors included 22 in Educational and Counseling Psychology, 11 in Psychology, 1 in Social Work, and 2 unclassified. The participants' year in college included 5 sophomores, 15 juniors, 8 seniors, and 8 in graduate school. Sixty-one percent had previous counseling, and fifty-six percent had participated in group counseling prior to this current experience. Participation in a counseling group was held in conjunction with the lecture portion of the group processes course and was one of several course requirements. However, participation in this research was not a course requirement. All group members signed statements of informed consent to participate in this study.

\section{Group Leaders}

Groups were facilitated by graduate students in counseling psychology who were enrolled in a year-long group counseling practicum. There were two white male doctoral students (ages 32 and 33), and two white female students (ages 45 and 47; the former a doctoral student, and the latter a master's student). As a prerequisite to this practicum, group leaders had satisfactorily completed two courses in group theory and practice, and one semester of group practicum. The leaders experience involved facilitating one or two groups. Group leaders were supervised by an experienced PhD-level psychologist 
during the study. Supervision was conducted both individually and in a group, for approximately 1.5 and 4.0 hours respectively, per week.

\section{Groups}

The thirty-six group members were divided up into 4 groups, containing 8, 9, 9, and 10 members, and were led by one of the four group facilitators for the entire semester. Groups met twice a week for 14 weeks, for a total of 28 sessions. Sessions lasted one hour and 20 minutes and there were at least five absences per group over the course of the group sessions. Groups were formed to maximize diversity in sex, age, ethnicity, previous group experience, and life experience across the groups, in order to create as heterogeneous a membership within each group as possible. The theoretical approach taken in leading these groups was a mix of interpersonal and interactional. Strategies included the following: (a) immediacy and process comments; (b) exploration of implicit references to the counselor or other group members to create a here-and now experience; (c) feedback strategies to make the client's communication more precise and congruent and make the client's behavior less rigid; and (d) reframing strategies designed to help the clients to behave differently in interpersonal situations. Goals for the group experience included: increasing members' ability to communicate effectively and increasing their willingness and capacity to trust others.

\section{Measures}

Session Evaluation Questionnaire (SEQ). The SEQ-Version 3 (Stiles, 1980) was given to measure the impact of the group session, and is comprised of a session evaluation section and post-session mood section. The subscales of the SEQ are comprised of common dimensions, which were identified from session ratings of 
participants in self-analytic groups (Stiles, Tupler, \& Carpenter, 1982). The common dimensions underlying session ratings resemble the general dimensions of connotative meaning identified in a research study by Osgood and his colleagues (Osgood, Suchi, \& Tannenbaum, 1957). According to Osgood et al. (1957), these dimensions include evaluation, or good vs. bad, potency, or strong vs. weak, and activity, or fast vs. slow. Also, these dimensions reflect the affective impact or connotative aspects of group interaction rather than the content or themes of sessions (Stiles et al. 1982). The SEQ measures two independent evaluative dimensions of participants' perceptions of their sessions, called Depth and Smoothness, and two global dimensions of their post session mood, called Positivity and Arousal (Stiles \& Snow, 1984). ,

To obtain these dimensions of post session evaluations and post session mood, factor analyses were conducted. According to Stiles (1980), separate factor analyses were performed on clients' and therapists' ratings in the first and second parts of the SEQ. This yielded four factor analyses in all. Factors were extracted by the principal-axis method and were rotated to an orthogonal, varimax criterion. According to Stiles (1980), two factors in the first part of the SEQ ("This session was:") were extracted for the clients' ratings, accounting for $33.2 \%$ and $27.8 \%$ (total $=61.0 \%$ ) of the common variance. Two factors in the first part of the SEQ ("This session was:") were also extracted for the therapists' ratings, accounting for $39.2 \%$ and $23.3 \%$ (total $=62.5 \%$ ) of the common variance. Factor 1 (depth) differentiated sessions described as valuable, full, special, deep, and good from sessions described as worthless, empty, ordinary, shallow, and bad. Factor 2 (smoothness) distinguished sessions described as smooth, pleasant, easy, and safe from sessions described as rough, unpleasant, difficult, and dangerous. 
According to Stiles (1980), in the second part of the SEQ ("Right now I feel:"), one large factor was extracted for client ratings, accounting for $54.3 \%$ of the common variance, and one was extracted for therapist ratings, accounting for $53.8 \%$ of the common variance. In each of these analyses, all 11 scales loaded between .60 and .85 (absolute values) on the first factor. All of the positive adjectives (e.g., happy, pleased, strong, sharp) were at one pole, in contrast with all the negative adjectives (e.g., sad, angry, weak, dull) at the other pole (Stiles, 1980).

Each dimension on the SEQ refers to a different evaluative state or mood factor. Depth refers to a session's perceived power and value. Depth is a part of the potency dimension, and is indexed by the terms powerful and deep, as opposed to weak and shallow. Depth has as been characterized as a "task dimension" (Stiles et al., 1990, p. 14), and has been shown reflect the "degree to which the group grappled with difficulty or personally meaningful issues" (Stiles et al., 1982, p. 244). Stiles et al. (1982) found depth to be more salient for members who reported less involvement and solidarity with the group. The researchers also found that depth was salient for members who here "less feminine, less socialized, less sociable, less responsible, and less inclined to use an inward frame of reference to describe themselves and others" (Stiles et al., 1982, p. 251). According to Stiles, Reynolds, Hardy, Rees, Barkham, and Shapiro (1994), the impact of sessions is distinctly different for participants who rate sessions with high depth - deep (i.e. powerful, effective) compared to participants who rate session with low depth shallow (i.e. weak, worthless).

Smoothness refers to a session's comfort, relaxation, and pleasantness. Smoothness is part of the evaluation dimension, and is indexed by terms smooth, easy, 
and relaxed as opposed to rough, labored, and tense. Smoothness has been characterized as a "socio-emotional dimension" (Stiles et al., 1990, p. 14), and refers to a "relaxed good feeling in a session" (Stiles et al. 1982, p. 244). Stiles et al. (1982) found smoothness to be the most important dimension for self-analytic group of college students. They found that smoothness was most salient who reported having more involvement and solidarity with the group. The impact of the session is different for participants who rate sessions with high smoothness - smooth (i.e. comfortable) compared to participants who rate sessions with low smoothness - rough (i.e. tense).

In later studies, researchers describe smoothness and depth as being two independent dimensions of session evaluation (Stiles \& Snow, 1984). It does not refer to a judgment that a session had a positive impact. Furthermore, sessions can be described as deep and smooth, deep and rough, shallow and smooth, or shallow and rough (Stiles, 1980).

Positivity refers to affective feelings of confidence and clarity as well as happiness and the absence of fear or anger (Stiles \& Snow, 1984). Participants can range in the level of positivity they feel after attending a group meeting. On one side of the continuum, a participant may feel confident, happy, or pleased. On the other side of the continuum, a participant may feel afraid, sad, or angry (Stiles et al., 1994).

Arousal is also related to affect and refers to feeling active and excited as opposed to quiet and calm. Some participants may feel energetic, fast, or excited, while others may feel peaceful, slow, or calm. In early studies, the subscale of positivity was the prevalent, and arousal was less defined. In the study by Stiles et al., (1980), researchers found that clients had postsession affect states that reflected a global positive vs. negative factor. This factor was named positive feelings, and was a single dimension of 
postsession mood (Stiles \& Snow, 1984). Stiles and Snow (1984) added arousal to the assessment of post session mood, along with positivity. The rationale behind this addition was that ratings of affect are "best construed in a two-dimensional semantic space: pleasure vs. displeasure (positivity) and activation vs. sleep (Russell, 1978, 1979).

The SEQ (Version 3) includes 24 seven-point bipolar adjective scales (see Appendix A). Respondents were instructed "Please place an 'X' on each line to show how you feel about this session." The stem "This session was:" precedes the first 12 items (session evaluation), bad-good, dangerous-safe, empty-full, easy-labored, worthlessvaluable, deep-shallow, rough-smooth, tense-relaxed, pleasant-unpleasant, powerfulweak, definite-uncertain, and special-ordinary. The stem "Right now I feel:" precedes the second 12 items (post-session mood), happy-sad, angry-pleased, active-still, uncertaindefinite, involved-detached, calm-excited, confident-afraid, alert-sleepy, friendlyunfriendly, slow-fast, joyful-sad, and quiet-aroused.

Each item was scored from 1 to 7 , reversed as appropriate, with higher scores indicating greater Depth, Smoothness, Positivity, or Arousal. According to Stiles, Gordon, and Lani (2002), a score for each of the four dimensions is calculated as the mean of the individual item ratings, rather than the sum of the item ratings. In addition to this, the dimension scores (i.e. Depth versus smoothness) lie on the same 7-point scale as the individual items (i.e. easy versus labored), making interpretation easier. The midpoint of each SEQ scale is 4.00, and the possible range (e.g., from maximum Roughness to maximum Smoothness) is 1.00 to 7.00. Internal consistency, measured by coefficient alpha, has been high for all SEQ indexes across a wide variety of conditions and settings (e.g., .90 for Depth, .93 for Smoothness; Reynolds et al., 1997). 


\section{Procedure}

Prior to the beginning of the groups, all participants filled out a consent form and a demographic information form. After each group session, participants filled out the SEQ and several other inventories not used in the study. Data were collected by the group leaders every two weeks and were stored in a safe place.

Actor-Partner Independence Model. When examining predictors of attendance based on results of the SEQ, I examined how individual scores and group scores on the SEQ influence individual attendance. In order to test the effect of the group (i.e., group post session mood and evaluation of the session) on an individual group member's attendance, a model that accounts for the non-independence inherent in group data is necessary, because traditional models assume independence of data. The Actor-Partner Interdependence Model (APIM; Kenny and Cook, 1999) is a model that allows researchers to measure group effects by accounting for the non-independence of data from small groups (Kashy \& Kenny, 2000).

The traditional APIM model is noted in Figure 5. Figure 6 depicts the APIM with the variables I am testing. In the traditional APIM, $X$ and $X^{`}$ represent the independent variables, and $\mathrm{Y}$ and $\mathrm{Y}^{`}$ represent the dependent variables or outcomes. From this model, it is important to note that there is a correlation between $\mathrm{X}$ and $\mathrm{X}^{\prime}$ and there is unexplained variance ( $U$ and $U^{`}$ ) in the outcome variables, $Y$ and $Y^{`}$, based on the nonindependence of the sample. The relationships between $\mathrm{X}$ and $\mathrm{Y}$, and $\mathrm{X}^{\prime}$ and $\mathrm{Y}^{\prime}$, are actor effects, and are denoted by horizontal arrows from $\mathrm{X}$ and $\mathrm{X}$ ' to $\mathrm{Y}$ and $\mathrm{Y}^{`}$, respectively. The relationship between $\mathrm{X}^{\prime}$ and $\mathrm{Y}$, and $\mathrm{X}$ and $\mathrm{Y}^{`}$, are partner effects and are denoted by the diagonal lines that intersect. 
Similarly, in my study group member and other group members represent the independent variables, and group member attendance and other group member attendance represent the dependent variables or outcomes. The relationship between group member SEQ scores and group member attendance, as well as other group member SEQ scores and other group member attendance, are actor effects. From Figure 8, these actor effects are denoted by horizontal arrows from group member to group member attendance and other group member to other group member attendance, respectively. The relationship between group member SEQ scores and other group member attendance, as well as other group member SEQ scores and group member attendance, are partner effects. From Figure 8, these partner effects are denoted by the diagonal lines that intersect.

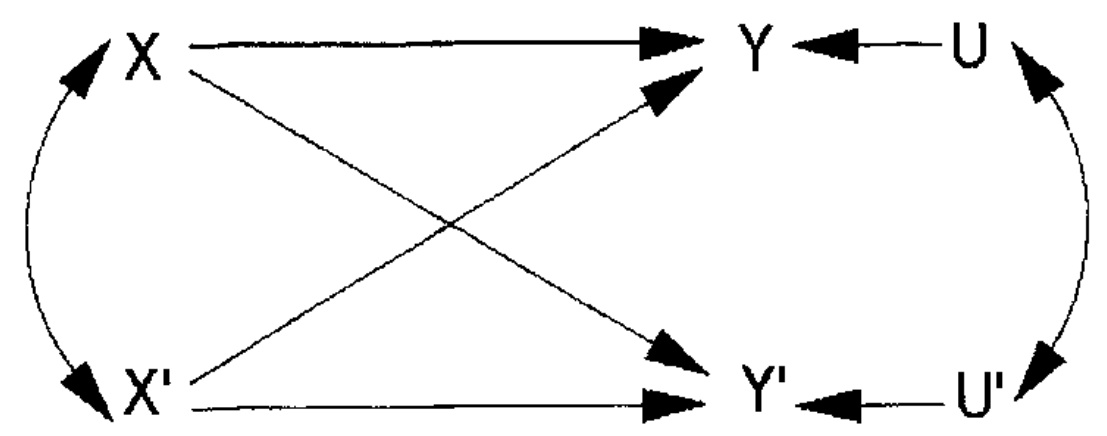

Figure 5. Traditional APIM.

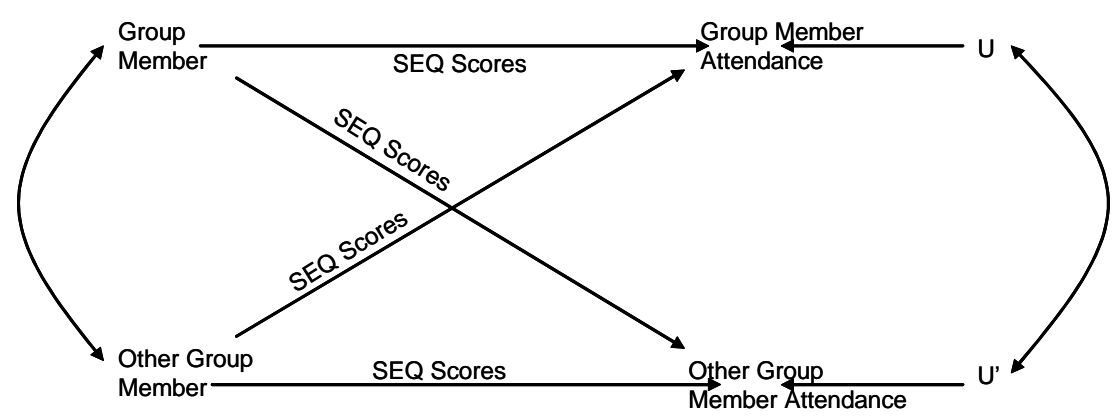

Figure 6. APIM with study variables. 


\section{Results}

The maximum number of participant session evaluation questionnaires (SEQs) that could have been obtained, if all participants attended all sessions and completed measures after each session was 1008 (36 participants x 28 sessions). A total of 907 SEQs were completed.

I also examined the overall means and standard deviations for post session evaluation and post session, and their correlations. Depth scores had the highest overall mean, $2.60(\mathrm{sd}=2.74)$. Postivity scores has the next highest overall mean, $2.21(\mathrm{sd}=$ 2.48). Arousal scores had overall mean of $2.07(\mathrm{sd}=2.27)$. Finally, smoothness scores had the lowest overall mean, $1.85(\mathrm{sd}=2.11)$. From Table 1, the largest correlation, .72, was between smoothness and positivity. The next largest correlation was for depth and arousal, at .58. The correlation between depth and positivity was .57. The correlation between positivity and arousal was .52. The correlation between depth and smoothness was .34. The correlation between smoothness and arousal was .30. The $\alpha$-level of all the correlations was at 0.05 , and all correlations were statistically significant, $\mathrm{p}<0.001$.

\section{Table 1. Correlations}

\begin{tabular}{lcccc}
\hline & 1 & 2 & 3 & 4 \\
1. Depth & Sessions & $(\mathrm{n}=1008)$ & & \\
2. Smoothness & - & $.344^{* *}$ & $.571^{* *}$ & $.580^{* *}$ \\
3. Positivity & - & - & $.724^{* *}$ & $.299^{* *}$ \\
4. Arousal & - & - & - & $.522^{* *}$ \\
\hline
\end{tabular}

Note. ${ }^{* *}$. Correlation is significant at the 0.01 level (2-tailed). 


\section{Completely unconditional HLM models}

One completely unconditional, three-level hierarchical linear model was run to partition the variance in attendance into sessions within group members, group members within groups, and between group variance components. Table 1 also displays these variance components. For attendance, $95.86 \%$ of the variance was within group members and across sessions, $0 \%$ of the variance was within groups and across group members and $4.14 \%$ of the variance was between groups. The $x^{2}$ statistics for the members and sessions within groups variance component $\left(\mathrm{df}=32, \mathrm{n}=1814, \mathrm{X}^{2}=24.05\right.$, $\mathrm{p}=.500)$, and between group variance component $\left(\mathrm{df}=3, \mathrm{n}=1814, \mathrm{X}^{2}=40.44, p<\right.$ $.001)$, meaning that there was not significant variance in attendance between members, but there was significant variance in attendance between groups.

\section{APIM Analyses}

Typically, the APIM uses the terms actor and partner to refer to two members of a dyad. In this study however, I am examining actor and partner effects in a group setting. The effects of the group member's and the other group members' scores for session depth, smoothness, positivity, and arousal on the group member's attendance were examined using the group adaptation of the Actor-Partner Interdependence Model (Kenny et al. 2002). Data for individuals in groups are (a) not independent and (b) can be influenced by the behaviors and perceptions other group members (Bonito et al., 2006). The APIM can be used to address the non-independence problem by nesting sessions within individual group members, and individual group members within groups in a multilevel model. The APIM analysis models the effects of both the individual group member's and the other group members' session evaluation and post-session mood. 
In the current study, the effects of a group member's session evaluation and postsession mood and the other group members' session evaluation and post-session mood (excluding the focal individual's session evaluation and post-session mood) on the focal member's attendance and the attendance of the other group members were examined with a two-level conditional model (sessions within group members and between group members). A two-level model was used because Kenny, Kashy, and Bolger (1998) indicate that small between group ICCs can be ignored for nested data even if the ICCs are statistically significant. Using a three-level model when the between groups ICCs are small unnecessarily reduces the power of analyses. An individual group member's attendance in a session was the dependent variable. An additional predictor of a group member's attendance was a term representing the change over time in attendance (this variable was created by centering sessions at the middle session). This growth term was included to control for the effects of time in the models. The APIM analyses were conducted in two hierarchical steps which are referred to as models.

Model 1 is the growth model in which change in group member attendance on a session-to-session basis is modeled. The equations for Model 1 assess the rate of change in group member attendance are:

Level 1: $y_{i j}=\pi_{0 i}+\pi_{l i} \operatorname{Session}_{i j}+e_{i j}$. (1)

Level 2: $\pi_{0 i}=\beta_{00}+u_{0 i}$, $\pi_{1 i}=\beta_{10}+u_{1 i}$.

The group member attendance for group member $\mathrm{i}$ at session $\mathrm{j}$ is $\mathrm{yij}, \pi_{0 i}$ is the intercept for group member i at Time 0 (Time 0 was set as the middle group session), therefore $\pi_{0 i}$ is the predicted group member attendance at the member's mid-point in treatment. The $\pi_{l i}$ coefficient indexes the quadratic rate of growth in attendance for 
group member $i$ across each session, and eij is the error term. In an HLM model the Level 1 parameters are the criterion variables in Level 2 of the model. One level 2 equation relates to the intercept coefficient in the Level 1 model and the other Level 2 equation is related to the quadratic slope coefficient at Level 1. Each group member's intercept, $\pi_{0 i}$, is a function of the grand mean of all group members' predicted attendance at Time $0, \beta_{00}$, plus each group member's intercept's deviation from the grand mean, $u_{0 i}$. Similarly, each group member's slope (i.e., quadratic rate of change in attendance), $\pi_{1 i}$, is a function of the average quadratic rate of change in attendance for all group members across sessions, $\beta_{10}$, plus each group member's slope deviation from the average rate of change, $u_{1 i}$.

Model 2 was used to assess the added effect of the group member's ratings and other group member ratings of the fours factors of depth, smoothness, positivity, and arousal on the group member's attendance. The four factors identified by the individual group member were modeled as a time varying covariates for each group member by adding the four factors parameters to the model (Tasca, Ramsay, Corace, Illing, Bone, Bissada et al., 2010). The equations for Model 2 are:

Level 1: $y_{i j}=\pi_{0 i}+\pi_{1 i} \operatorname{Session}_{i j}+\pi_{2 i}$ Group Member Actor Depth ${ }_{i j}+\pi_{3 i}$ Other Group Member Actor Depth ${ }_{i j}+\pi_{4 i}$ Group Member Partner Depth $_{i j}+\pi_{5 i}$ Other Group Member Partner Depth ${ }_{i j}+\pi_{6 i}$ Group Member Actor Smoothness $_{i j}+\pi_{7 i}$ Other Group Member Actor Smoothness $s_{i j}+\pi_{8 i}$ Group Member Partner Smoothness $_{i j}+$ $\pi_{9 i}$ Other Group Member Partner Smoothness ${ }_{i j}+\pi_{10 i}$ Group Member Actor Positivity $_{i j}+\pi_{11 i}$ Other Group Member Actor Positivity $i j+\pi_{12 i}$ Group Member Partner Positivity $_{i j}+\pi_{13 i}$ Other Group Member Partner Positivity $i j+\pi_{14 i}$ Group Member Actor Arousal $i j+\pi_{15 i}$ Other Group Member Actor Arousal ${ }_{i j}+\pi_{16 i}$ Group Member PartnerArousal ${ }_{i j}+\pi_{17 i}$ Other Group Member Partner Arousal $i j+e_{i j}$.

Level 2: $\pi_{0 i}=\beta_{00}+u_{0 i}$,

$\pi_{1 i}=\beta_{10}+u_{1 i}$

$\pi_{2 i}=\beta_{20}+u_{2 i}$,

$\pi_{3 i}=\beta_{30}+u_{3 i}$, 


$$
\begin{aligned}
& \pi_{4 i}=\beta_{40}+u_{4 i}, \\
& \pi_{5 i}=\beta_{50}+u_{5 i}, \\
& \pi_{6 i}=\beta_{60}+u_{6 i}, \\
& \pi_{7 i}=\beta_{70}+u_{7 i}, \\
& \pi_{8 i}=\beta_{80}+u_{8 i}, \\
& \pi_{9 i}=\beta_{90}+u_{9 i}, \\
& \pi_{10 i}=\beta_{100}+u_{10 i}, \\
& \pi_{11 i}=\beta_{110}+u_{11 i}, \\
& \pi_{12 i}=\beta_{120}+u_{12 i}, \\
& \pi_{13 i}=\beta_{130}+u_{13 i}, \\
& \pi_{14 i}=\beta_{140}+u_{14 i}, \\
& \pi_{15 i}=\beta_{150}+u_{15 i}, \\
& \pi_{16 i}=\beta_{160}+u_{16 i} \\
& \pi_{17 i}=\beta_{170}+u_{17 i},
\end{aligned}
$$

where $\pi_{2 i}$ represents the quadratic rate of change in attendance for a group member based on a group member's depth scores, $\pi_{3 i}$ represents the quadratic rate of change in attendance for other group members based on other group members' depth scores, $\pi_{4 i}$ represents the quadratic rate of change in attendance for other group members based on a group member's depth scores, and $\pi_{5 i}$ represents the quadratic rate of change in attendance for a group member based on other group members' depth scores. In terms of smoothness, $\pi_{6 i}$ represents the quadratic rate of change in attendance for a group member based on a group member smoothness scores, $\pi_{7 i}$ represents the quadratic rate of change in attendance for other group members based on other group members' smoothness scores, $\pi_{8 i}$ represents the quadratic rate of change in attendance for other group members based on a group member's smoothness scores, and $\pi_{9 i}$ represents the quadratic rate of change in attendance for group members based on other group members' smoothness scores. In terms of positivity, $\pi_{10 i}$ represents the quadratic rate of change in attendance for a group member based on a group member positivity scores, $\pi_{11 i}$ represents the quadratic rate of change in attendance for other group members based on other group members' positivity scores, $\pi_{12 i}$ represents the quadratic rate of change in attendance for 
other group members based on a group member's positivity scores, and $\pi_{13 i}$ represents the quadratic rate of change in attendance for a group member based on other group members' positivity scores. Finally, in terms of arousal, $\pi_{14 i}$ represents the quadratic rate of change in attendance for a group member based on a group member arousal scores, $\pi_{15 i}$ represents the quadratic rate of change in attendance for other group members based on other group members' arousal scores, $\pi_{16 i}$ represents the quadratic rate of change in attendance for other group members based on a group member's arousal scores, and $\pi_{17 i}$ represents the quadratic rate of change in attendance for a group member based on other group members' arousal scores.

In HLM analyses the error terms are assumed to be normally distributed, with a mean of zero. There is a variance component associated with each error term. The session within-group member variance associated with $e_{\mathrm{ij}}$ error term is labeled $\sigma^{2}$. The between-group member variance in intercepts associated with $u_{0 \mathrm{i}}$ error term is labeled $\tau_{0}$. Likewise $\tau_{1}$ is the between-group member variance in linear growth associated with $u_{1 \mathrm{i}}$ error term. In this manner each $u$ error term has a $\tau$ variance component associated with it.

Singer and Willett (2003) suggested that researchers determine the appropriate growth model to test by performing visual inspection of the individual ordinary least squares (OLS) plots to determine if a linear or nonlinear model would provide the best fit for the data. A visual inspection of the OLS plots suggested that a quadratic growth model would be most appropriate for the attendance data.

The quadratic growth model for session depth, Model 1, showed that the predicted mid-session logged attendance rate for the group members was $2.45(\mathrm{SE}=0.13 ; \mathrm{t}=$ 
19.06; $\mathrm{p}<0.000)$. The predicted mid-session logged attendance rate for the other group members was $0.55(\mathrm{SE}=0.10 ; \mathrm{t}=5.78 ; \mathrm{p}<0.000)$. The average rate of quadratic growth was $0.004(\mathrm{SE}=0.000454 ; \mathrm{t}=9.49 ; \mathrm{p}<0.000$. This quadratic growth terms indicates that there was a "U" shaped curve for attendance with attendance increasing on either side of the mid-session.

In Model 2, I added the group member and other group member scores for the four factors of depth, smoothness, positivity, and arousal. The gamma statistics, standard errors and $t$ values for Model 2 for attendance are displayed in Table 2. As seen in the table, the quadratic term was significant, $\gamma=0.004, p=.001$. This means that attendance increased in a quadratic manner from the mid-session.

Group Member Actor Effects. There was one significant group member actor effect, see Figure 7. Group member positivity $(\gamma=-0.052, \mathrm{p}=.024)$, was negatively related to group member attendance. When there was a low level of positivity for a group member mid-session, the estimated probability of a group member attending the subsequent session was .827 . When there was an average level of positivity for a group member mid-session, the estimated probability of a group member attending the subsequent session was .819. When there was a high level of positivity for a group member mid-session, the estimated probability of a group member attending the subsequent session was .812 .

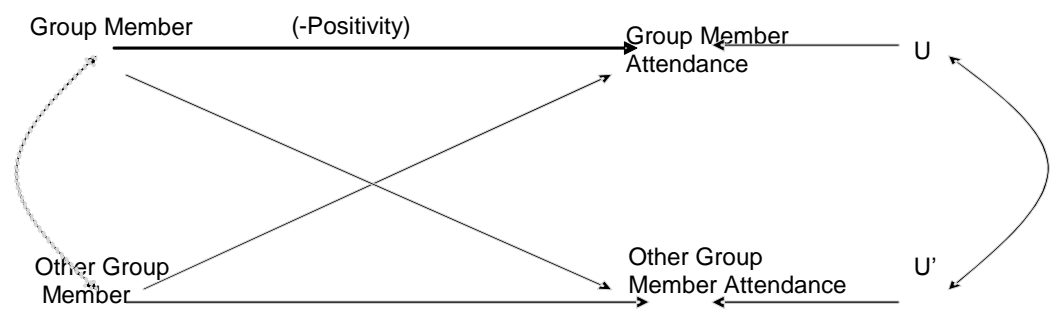

Figure 7. APIM with group member actor results. 
Group Member Partner Effects. There were no significant relationships between a group member's SEQ scores and other group member's attendance, see figure 8.

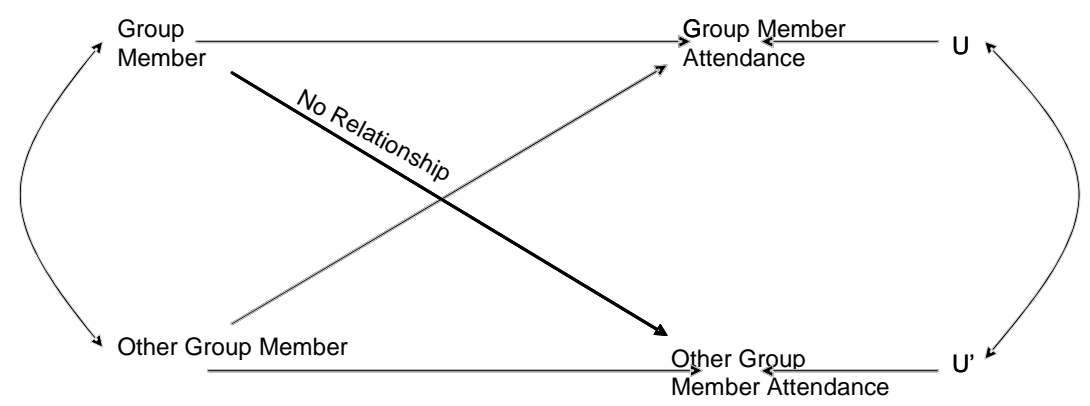

Figure 8. APIM with group member partner results.

Other Group Member Actor Effects. There were three significant actor effects for the other group members, see figure 9. Other group members' Depth $(\gamma=-0.307, \mathrm{p}=$ $.000)$, was negatively related to the probability that all of the other group members would attend the subsequent session. When there was a low level of depth for other group members' at the mid-session, the estimated probability of all other group members attending the subsequent session is .59. When there was an average level of depth for other group members at the mid-session, the estimate probability of all other group members attending the subsequent session is .52 . When there was a high level of depth for other group members at the mid-session, the estimated probability of all other group members attending the subsequent session is .44. Other group member smoothness $(\gamma=$ $0.305, \mathrm{p}=.001)$, and other group member Arousal $(\gamma=0.281, \mathrm{p}=.003)$ were positively related to other group member attendance. When there was a low level of smoothness for other group members' mid-session, the estimated probability of all other group members attending the subsequent session was .443 . When there was an average level of smoothness for other group members' mid-session, the estimated probability of all other 
group members attending the subsequent session was .519. When there was a high level of smoothness for other group members' mid-session, the estimated probability of all other group members attending the subsequent session was .594. For arousal, when there was a low level of arousal for other group members' mid-session, the estimated probability of all other group members attending the subsequent session was .449 . When there was an average level of arousal for other group members' mid-session, the estimate probability of all other group members attending the subsequent session was .519. When there was a high level of arousal for other group members' mid-session, the estimated probability of all other group members attending the subsequent session was .588.

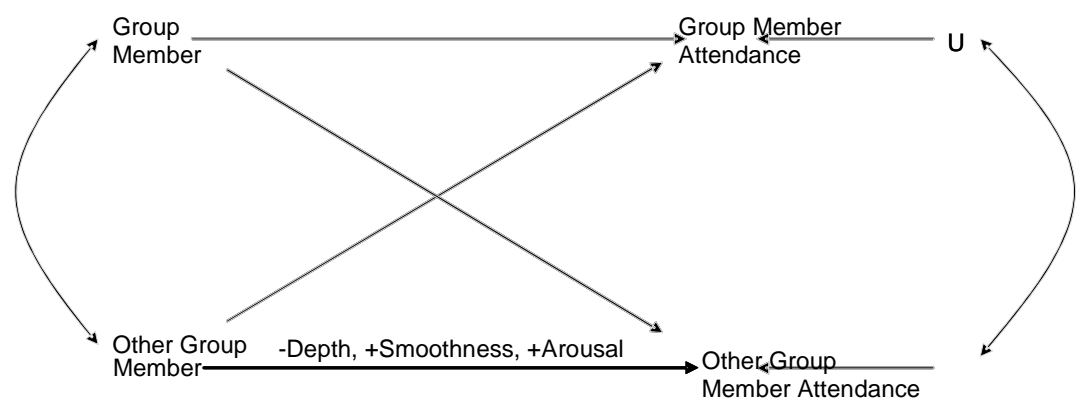

Figure 9. APIM with other group member actor results.

Other Group Member Partner Effects. There were three significant partner effects for other group members, see figure 10. Other group member Depth $(\gamma=-0.126$, $\mathrm{p}=.000$ ), was negatively related to group member attendance. When there was a low level of depth for other group members' mid-session, the estimated probability of a group member attending the subsequent session was .837 . When there was an average level of depth for other group members' mid-session, the estimate probability of ar group member attending the subsequent session was .819 . When there was a high level of depth for other group members' mid-session, the estimated probability of all other group members 
attending the subsequent session was .80. Other group member smoothness $(\gamma=0.139, \mathrm{p}$ $=.025)$, and other group member Arousal $(\gamma=0.1, \mathrm{p}=.050)$, were positively related to group member attendance. For smoothness, when there was a low level of smoothness for other group members' mid-session, the estimated probability of a group member attending the subsequent session was .798. When there was an average level of smoothness for other group members' mid-session, the estimate probability of a group member attending the subsequent session was .819. When there was a high level of smoothness for other group members' mid-session, the estimated probability of a group member attending the subsequent session was .839. For arousal, when there was a low level of arousal for other group members' mid-session, the estimated probability of a group member attending the subsequent session was .804 . When there was an average level of arousal for other group members' mid-session, the estimated probability of a group member attending the subsequent session was .819. When there was a high level of arousal for other group members' mid-session, the estimated probability of a group member attending the subsequent session was .834 .

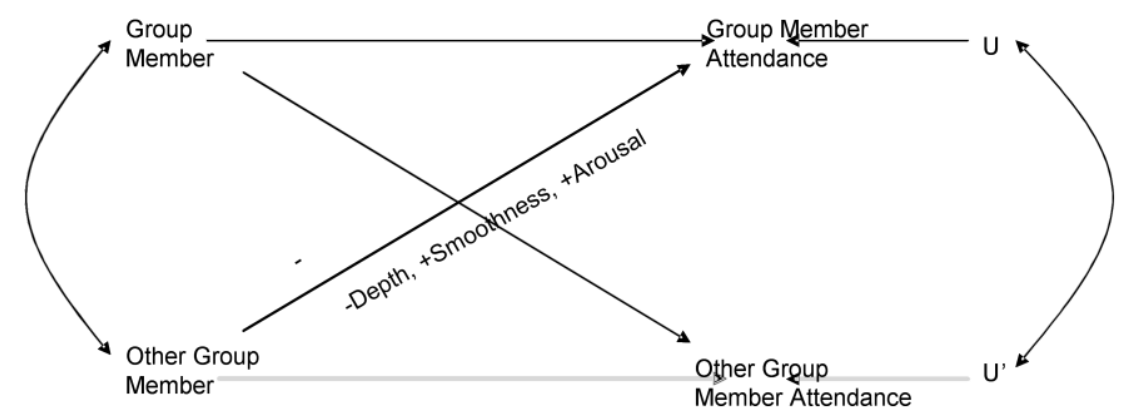

Figure 10. APIM with other group member partner results 


\section{Discussion}

Although this study was novel in that it examined how in-session factors affect attendance, it is not the first study to examine group processes at the session, person, and group levels. As mentioned earlier, Miles et al. (2009) conducted a study examining individual and group factors that influenced individual behaviors. Specifically, Miles, et al. (2009) examined the relationship between the amount and consistency of the previous intimate behaviors of the other group members the individual's own previous intimate behaviors, and the individual group member's level of current intimate behaviors. In addition to the Miles et al. (2009) study, Kivlighan (in press) also conducted a study examining factors at the session, person, and group level. In his study, Kivlighan (in press) examined the relationship between a group member's and other group members' perceptions of therapeutic factors and the member's session evaluation. He examined the relative variance in the perception of therapeutic factors at the session, person and group levels. Kivlighan (in press) found little variance in the perception of therapeutic factors at the group level. Unlike the Miles et al. (2009) study where group variance was large, the current study and the Kivlighan (in press) study found little variance at the group level. In this study and the Kivlighan study there were only four groups whereas in the Miles et al. study there were eight groups. The smaller number of groups in this study and in Kivlighan (in press) may account for the relative small amount of between group variance in these two studies.

In this study, the majority of the variance in attendance was between sessions (within members and groups). For attendance in both individuals and other group members, between session variance which was within group members and between 
sessions, accounted $95.86 \%$ of the total variance. This finding indicates attendance was more of a function of what was happening between sessions, rather than something attributable to how an individual or group behaves.

By contrast, $0 \%$ of the variance in attendance was within groups and across group members and only $4.14 \%$ of the variance of attendance was across groups. This finding indicates that attendance does not appear to be a function of the individual member's characteristics and only a very small function of the group. Rather, over $96 \%$ of the variability in attendance appears to be a function of the sessions. Overall, the variances appear to indicate that there are different types of sessions. Whether an individual is high or low in their attendance appears to be a function of what is happening in a particular session, rather than something about that individual or the particular group he or she is a part of.

These findings indicate the importance of examining the variation in group processes across sessions. The findings also provide an argument for not relying on group members' ratings of group processes at a single point in time. Kivlighan, Coleman and Anderson (2000) encouraged group researchers to pay more attention to time when studying group processes. If sessions are not examined researchers are missing the most important source of variation in group member attendance.

Group Member Actor Hypotheses. I hypothesized that there would be a positive relationship between a group member's depth, smoothness, positivity, and arousal scores and a group member's attendance in subsequent sessions. Contrary to my hypothesis, there was an inverse relationship between a group member's positivity scores and a group member's attendance in subsequent sessions. In other words, when a group 
member's positivity was higher than average at mid-session, the likelihood that a group member would attend a subsequent session was lower than average. In addition to this, there was not a significant relationship between a group member's depth, smoothness and arousal scores and a group member's attendance in a subsequent session.

Stiles et al. (1988) found that after sessions, clients' post session mood was rated more positively by both the external raters and the clients themselves. Joyce and Piper (1990) found that improved outcome was related to client ratings of positivity. Based on these studies, I hypothesized that group member positivity scores would be positively related to group member attendance. Finding that group member positivity had an inverse relationship with group member attendance was indeed surprising.

To begin to explain these findings, there may be a mindset that too much group member positivity may affect the attendance of a group member. Mallinckrodt (1993) stated that, in addition to arousal, too much positivity may be counterproductive to continuing therapy. An explanation of Mallinckrodt's (1993) findings may be rooted in a client's perception of their problem. There is a pervading theory in psychotherapy that a client must have some degree of conflict or interpersonal tension for them to begin therapy (Hill, 2004). When seeking help, individuals may have social motives, such as the need for affiliation, that ultimately guide their decisions to join a group (Forsyth, 1999), and according to Schachter (1959), people ultimate join groups to affiliate in order to achieve cognitive clarity. To expand on this idea of affiliating to achieve clarification, Forsyth (1999) believed that an important purpose of a group is to provide individuals with reassurance about their problems and "fear-allaying information about their situation" (p. 96). In my study, goals of the group were to increase members' ability to 
communicate effectively and increase their willingness and capacity to trust others. If after several group sessions, a group member begins to feel a high level confidence or happiness (positivity) about their ability to communicate and/or trust others from other group members, as opposed to feeling fear or tension, it may cause a group member to feel as if they no longer need to be in a group, and consequently they miss sessions. This again may be based the theory that a group member's confidence or happiness within the group may give them the idea that they no longer need therapy because their fears, insecurities, and/or doubts have been allayed.

The lack of findings on group member actor depth, smoothness, and arousal may reflect several explanations. First, similar with the Kivlighan (in press) study, group member actor effects were almost non-existent. Except for the ratings of positivity, the group member's evaluation of a session and post-session emotions do not seem to affect his or her attendance in later sessions. This may suggest that there partner effects (other group members) are more important in predicting a member's behavior than her/his own actor effect. The influence of the group is a well-established group dynamics principal. As early as 1952, Asch showed that individuals would suppress their own perceptions to conform to the perception of the other group members. It is surprising that an individual's own evaluation of the session would show so few relationships to their own attendance. However, as noted by Forsyth individuals tend to overestimate their own influence and underestimate the influence of the group.

Another possibility of limited group member actor effects has to do with the participants and location of the group. Because the participants in this study were college students who participated in groups as part of a course, there may not have been 
willingness for members to engage in deep and powerful sharing of emotions, as compared to therapy groups in another setting. For example, as group member depth increased in session, group members may have felt vulnerable and uncomfortable sharing with peers, affecting their subsequent attendance. This may be due to, in part, social desirability factors between themselves and other group members. It also may be due to group norms that were established early within the groups.

Finally, the lack of actor factors affecting attendance of group member's may also suggest that there are external factors outside of the group affecting a group member's attendance. Future studies need to take possibilities into consideration.

Group Member Partner Hypotheses. My group member partner hypothesis was that there would not be a significant relationship between a group member's depth, smoothness, positivity, and arousal scores and other group members' attendance in subsequent sessions. This hypothesis was correct-there were no significant relationships between a group member's scores and other group member's attendance. In other words, a group member's scores did not affect other group member's subsequent attendance.

This finding reflects a trend that was mentioned earlier. Similar to the Kivlighan (in press) study, my study found that group member partner effects were not significant. The group member's evaluation of a session and post-session emotions do not seem to affect other group member's attendance in later sessions. This may suggest that one person's evaluation or emotions about a session do not affect the attendance of other members.

One theory behind these findings is rooted in the concept of social influence, or "interpersonal processes that change group members thoughts, feelings, and behaviors" 
(Forsyth, 1999, p.175). According to Forsyth (1999), much of the direction of social influence flows from the group to the individual, not vice versa. In other words 'majority influence', or a group's effect on the individual, is more common in most group situations than 'minority influence', or the influence an individual has on the group. My group member partner hypothesis was based, in part, on the theory of social influence, and particularly with a focus on minority influence.

There are some situations where minority influence, or the individual influencing the group, is prevalent. First, minority influence is likely to occur when groups have minorities who offer compelling arguments that contradict the majority are more influential than individuals who fail to refute the majority's position (Clark, 1990). Second, minority influences is likely to occur when minorities are more influential when the majority is uncertain about the correctness of its position (Witte, 1994). Finally, according to Moscovici (1994) minority influence occurs when minorities influence other group members indirectly through 'conversion'. Forsyth (1999) defines conversion as a "change that occurs when group members personally accept the influencer's position". An example of a minority influence through the use of conversion is a study conducted by Nemeth and Walker (1974).

In this study, Nemeth and Walker (1974) examined several groups of five members each and instructed each group to a reach a consensus on a decision. In the experimental group, a confederate member (minority) of a five-person group argued for a lower monetary claim to be given to a victim of the personal-injury case, while the majority argued for a higher monetary claim. Although the ultimate decision was to go with the majority opinion and award the victim higher monetary claim, in a second case, 
the subjects who were exposed to a confederate member were more likely to give significantly smaller awards that subjects who were never exposed to a confederate member (Nemeth \& Walker, 1974).

The Nemeth and Walker (1974) study is a classic example of a situation where minority influent is prevalent. First, the confederate offered compelling arguments to the majority to offer a lower claim. Second, the majority was uncertain about its position to give a higher monetary claim, even though this uncertainty not apparent. Third, a conversion took place, since subjects who were exposed to the confederate gave substantially less in subsequent cases. While minority influence with a conversion factor is evident in the Nemeth and Walker (1974) study, the likelihood of minority influence occurring in my study is low.

First, in Nemeth (1974), minority influence occurs partly because the minority offered compelling arguments that contradicted the majority and were more influential than individuals who fail to refute the majority's position (Clark, 1990). The goal of the Nemeth and Walker (1974) group was consensus- an agreed-upon, unanimous decision. On the other hand, in my study the goal of the group was not consensus. The goal of my group was to increase members' ability to communicate effectively and increase their willingness and capacity to trust others. While there could have been dissent on some topics within my group, the fact that there was not a goal of consensus decreased the opportunity for minority influence. Second, in Nemeth (1974), minority influence occurs partly because the minority is more influential when the majority is uncertain about the correctness of its position. In my group, it would seem difficult to contradict or refute the majority position given that the goal of the group was improve communication and trust. 
Further, the participants in my study were students who were in a counseling group as part of a group counseling course requirement and groups were facilitated by advance doctoral students. This meant that the instruction students were receiving was being augmented by the groups they were participating. Theoretically, participants were learning the group processes they were simultaneously experiencing in groups. Refuting or contradicting the majority, and the group facilitator for that matter, seems implausible based on the population and setting.

It is my position that group member's depth, smoothness, positivity, and arousal scores did not affect the attendance of other group members because the group members were not in a group setting or environment where minority influence could occur. When the other group members have high SEQ scores and a lone group member has low SEQ scores, according the social influence theory, the low group member's scores will not have an effect on the other group members' outcome (i.e. attendance). Although the attitude and behaviors of the group member may indicate a minority stance (i.e. feelings of session shallowness and roughness, and affective feelings of fear and dejection), these attitudes and behaviors will not have an effect on other group members' subsequent attendance.

But aside from social influence theory, another unexplored explanation for the lack of relationship between a group members SEQ scores and other group members attendance may be that a group member variable not examined in this study is related to other group members' attendance. For instance, a group member's characteristics within the group, such as a group monopolizer, may significantly affect the attendance of other group members. Yalom (1995) states that unresolved issues with group monopolists may 
have a detrimental effect on group cohesiveness. Further, he notes that the effects of a monopolist are noted by indirect effects on the group, "off-target fighting, absenteeism, dropouts, and subgrouping” (p.370). From this finding, group member characteristics may be an area for further studies examining individual factors that affect group attendance.

Other Group Member Actor Hypothesis. My other group member actor hypothesis was that there would be a positive relationship between other group members' depth, smoothness, positivity, and arousal scores and other group members' attendance in subsequent sessions. I did find that there was a positive relationship between smoothness and arousal scores and attendance. In other words, when other group members' smoothness or arousal score were higher than average after mid-session, the likelihood that all other group members would attend a subsequent session was higher than average. Contrary to my hypothesis, there was an inverse relationship between other group members' depth scores and other group members' attendance in subsequent sessions. In other words, when other group members' depth was higher than average after midsession, the likelihood that all other group members would attend a subsequent session was lower than average. Also, I did not find a significant relationship between other group members' positivity scores and other group members' attendance.

Unlike the group member actor results, where only positivity was related to group member attendance, the smoothness and arousal of other group members was positively related to other group member attendance. However, there have been studies that have shown no relationship or an inverse relationship between smoothness with better outcomes. Tryon (1990) found that smoothness or comfort with session was not related 
to client return. Her study suggested that clients need more than a "relaxed, easy, pleasant, smooth, comfortable experience to influence their return for further sessions" (p. 251). Similarly, Nash and Garske (1988) found that clients who rated having greater SEQ smoothness in initial sessions more likely to dropout later than clients who rated having less SEQ smoothness. Unlike these researchers, Stiles (1980) that smoothness was related to session outcome. He found that clients felt more positively about sessions they rated as smooth or comfortable. Stiles' (1980) findings were the basis for my hypothesis.

As a matter of explanation, group cohesiveness may be the reason for this relationship between smoothness, arousal, and attendance. Yalom (1995) states that the "greater the patient's attraction to the group, the more inclined that person will be to continue membership" (p. 62). Attraction to the group, as characterized by the ease of the session (smoothness) and the involvement and alertness (arousal) of the groups' members, may be related to higher levels of continuity in attendance.

Another factor explaining for the relationship between smoothness, arousal, and attendance is the pool of participants. According to Yalom (1995), cohesiveness does not mean comfort. Further, he notes that in truly cohesive groups, there is both greater acceptance, intimacy, and understanding, but also greater development and expression of hostility and conflict. Because the participants in this study were college students who participated in groups as part of a course, there may not have existed as much hostility and conflict in these groups compared to therapy groups in another setting. This may be due to, in part, social desirability factors between themselves and the group leaders. It also may be due to group norms that were established early within the groups. In other 
therapy groups, therefore, there may exist higher levels of conflict and hostility, but there also may exist higher levels of cohesiveness.

In terms of the impact of depth, there have been mixed findings about the role depth has on group outcome. On the one hand, high scores of depth are usually correlated with better outcome. Tryon (1990) found that clients return to sessions when they rated the sessions as "deep, valuable, special, powerful, and full-the items on the SEQ depth scale." Also, she found that clients who dropped out of groups rated their initial interview as less deep. However, there are other studies where depth did not seem to be related to client outcome. Stiles et al. (1990) found that clients who considered there sessions as valuable and powerful (deep) did not have better outcomes that client's who considered their sessions as worthless and weak (shallow).

Using Tryon's (1990) findings as the basis of my hypothesis, I was expecting that high scores of depth would be positively linked with attendance. Instead, I found that higher depth of other group members was related to lower rates of attendance of all other group members in subsequent sessions. One explanation for this again may be rooted in the lack of group cohesiveness. Due to the fact that there may have been less opportunities for conflict and hostility in these student groups, these groups may have only been superficially cohesive, and in fact not be very deep and powerful. When instances in these groups arose where there were opportunities for more depth, it may have caused other group members to miss sessions.

Other Group Member Partner Hypothesis. My other group member partner hypothesis was that there would be a positive relationship between other group members' depth, smoothness, positivity, and arousal scores and a group member's attendance in 
subsequent sessions. I did find that there was a positive relationship between smoothness and arousal scores and attendance. When other group members' smoothness or arousal scores were higher than average after mid-session, the likelihood that a group member would attend a subsequent session was higher than average. Contrary to my hypothesis, there was an inverse relationship between other group members' depth scores and a group member's attendance in subsequent sessions. In other words, when other group members' depth was higher than average after mid-session, the likelihood that a group member would attend a subsequent session was lower than average. Also, I did not find a significant relationship between other group members' positivity scores and a group member's attendance.

This finding reflects the social influence theory that was mentioned earlier. According to Forsyth (1999), much of the direction of social influence flows from the group to the individual. In other words 'majority influence', or a group's effect on the individual, is more common in most group situations than 'minority influence', or the influence an individual has on the group. My other group member partner hypothesis was based, in part, on the theory of social influence, and particularly with a proclivity towards majority influence.

Sherif (1936), Newcomb (1943), and Asch (1957) found that when an individual's attitudes and outlooks shift when the group's attitudes and outlooks shift. According to Sherif, (1936) norms develop over time and reflect how people in groups come to develop standards that serve as frames of reference for behavior and perception. According to Singer (1990), any group that plays a significant role in our life, such as family, colleague as work, or a group we would like to claim membership becomes a 
reference group. Related to this, Newcomb (1943) found that students' political attitudes changed as their reference group changed. Finally, Asch's (1952) visual acuity tests indicate that individual subjects sometimes cannot resist the pressure to conform and speak out against a majority view.

These researchers' findings provide the explanation for my other group member hypothesis findings. Group members conform to the norms of the reference group, which are provided by the other group members. In my study, other group members had normative influence, and caused group members to feel, think, and act in ways that are consistent with group norms (Forsyth, 1999). This finding is not surprising also, given the location and participants in the group. It seems that in groups of college students, there would be a convergence of members towards consensus and stability.

It is interesting that other group member partner findings are identical to the other group member actor findings-depth, smoothness, and arousal were each significant. This finding suggests that not only do other group members influence each other, but they also influence a group member.

This finding also suggests that the most powerful factor affecting attendance is other group members. Other group members accounted for six of the seven relationships found between SEQ scores and attendance. Although these groups developed norms over time, group members seemed to not react well to sessions that were high on depth. The increase in other group members' depth, as noted by its value, power, and effectiveness after the mid-session, decreases the attendance rate of both group members and other group members. It seems that as group members and other group members pass the mid- 
session point, they want to have less depth and more smoothness or arousal in sessions, and will subsequently attend more sessions when these conditions are met.

In terms of depth, I found that higher depth of other group members was related to lower rates of attendance of a group member in subsequent sessions. One explanation for this again may be rooted in the lack of group cohesiveness. Related to this, Yalom (1995) explains that reason for an inverse relationship between deep and valuable (depth) sessions and outcome may be a group member's problems with intimacy. As stated earlier, Miles et al. (2009) found a positive relationship between a group's mean level of intimate behaviors, and an individual's intimate behavior. This suggests that intimate behaviors of a group affect individual behavior. Further, Yalom (1995) notes that, among other reasons, individuals drop out of group therapy because of problems related to intimacy. From my study, it is unclear if problems with intimacy affect a group member's attendance. Future studies on attendance should test this theory.

\section{Limitations}

It is important to address some of the limitations of the study. First, due to the fact these results are based on a subject measure, it is possible that the findings reflect the operation of monomethod bias (Campbell \& Fiske, 1958). For example, it would be possible to obtain measures post-session evaluation and mood from outside observers or from group leaders. The study would be strengthened by the addition of multiple measures of post session mood and pose-session evaluation beyond just using one measure.

Next, the results are based on correlations. Therefore, it is impossible to determine any causal relationships between factors of post-session evaluation and post- 
session mood and attendance. It may be that a third, unmeasured variable, is responsible for the observed relationships between individual and group evaluation and mood factors and attendance.

Second, the group members were students in personal growth groups who were fulfilling a course requirement, which may have several implications for results. First, although the explicit purpose of these groups was to help group members become aware of their interpersonal strengths and weaknesses, students post session evaluation and mood may be different than those of people seeking personal growth or therapy. Gender may have also played a role in the findings as over $88 \%$ of the participants were women. Thus, an attempt to replicate these results with clients in psychotherapy groups with a more heterogeneous gender sampling would be an important next step. Second, there may have been interdependence with student group members dependent on other student group members to provide normative attitudes and behaviors. For instance, student's ratings of post-session evaluation may have influenced by the level of comfort sharing with their peers or the extent to which higher ratings might garner them higher course grades. The prominence of certain attitudes and behaviors in addition to their roles as students in a college setting may be a result of this interdependence. Having common interdependent goals as in the interpersonal growth groups may be different than the situation in counseling and therapy groups. Counseling and therapy group members may have more individualistic goals than students enrolled in a course, and therefore may be less interdependent. Evaluation and mood factors may play a more prominent role in counseling and therapy groups, than in academic settings. 
In addition to this, measures were collected every two weeks instead of after every session. This may increase the risk that absences did not occur, but were in fact still recorded based on missing measures. Because groups were lead in an academic setting with advanced doctoral students, actual missing data more likely reflected absences than missing measure. Due to the population of students and academic session, there seems to be less of a risk that participants' measures would be lost to neglect.

Another consideration is the role of the group leader on outcome. Sy, Côte, and Saavedra (2005) found that when group leaders of self-managing groups were in a positive mood during sessions, individual group members experienced more positive and less negative mood. Also, the group had a more positive and less negative affective tone. Sy et al. (2005) ultimately found that the moods of group leaders were transferred to other group members. Due to the fact that the mood of the group leader was not considered in my study, it will be important to examine whether the relationship between moods of leaders and group members' is the same across different groups.

Another limitation is that the results are based on a relatively small number of group members. The coefficients are very stable because they are based on over 900 session data points. In this study, power is determined largely by the number of group members in the study and by the number of sessions. Due to the fact that there was no person-level variance and low group-level variance, power was not an issue. As a result, I have moderate power to detect effects- a low amount of power did not contribute to nonsignificant findings.. Therefore, it is unlikely that the significant effects observed are spurious. The likelihood is that I was not able to detect some small true effects. These results need to be replicated with larger samples. 
The results of this study suggest a number of avenues for future research. As noted above replication in other types of groups will be important, especially to see if the role of post session evaluation and post session mood has similar findings in other settings and populations, especially therapy groups outside of classroom settings. It is also important for researchers to continue to use multilevel designs when examining therapeutic factors. It is unclear how often unaccounted for nonindependence has affected the results of previous studies. It will also be important to examine group and individual effects with other important group processes.

Finally, early studies have examined pretherapy person factors affecting outcome (McCallum, Piper, \& Joyce, 1992; MacNair \& Corrazini, 1994; Kelly \& Moos, 1993). This study tried to expand the group literature by examining in-group processes. Perhaps the next step in the literature would be to examine how both pretherapy factors and ingroup factors influence attendance.

This study showed that how the group members and other group members had a significant effect on attendance. These findings get to the essence of interactive group treatments. Various session-level factors that influence the individual group member's attendance are an important area for further study. The APIM approach is an important tool for conducting these types of analyses. The Miles et al. (2009), Kivlighan et al. (in press), and Bonito et al. (2006) studies and this study examined the group's influence on group member behavior (different types of participation). Important group processes that undergird small group treatments, including studies that further examine group's influence in other affective and cognitive domains, will be advanced when researchers provided more studies that examine individual and group process simultaneously. 
Appendix A.

SESSTOH EVALUATIOH QUEST TONNATRE

This sension was:

coon

SAFR

FUTI

I.ARORED

WALMBS

SHeTton

$5 \times 007 \mathrm{Ft}$

TEI.AXED

UNPTEASAYT

WERK

WNOERTATN

SPECIAL

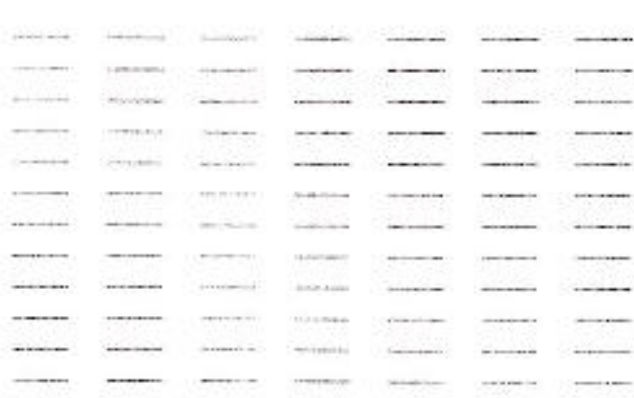

EAD

DA.NGEROUS

FENTY

EASY

WORTHLSSS

DEEP

ROUGH

TENST

PIEASANT

PCWERFCT,

DEF ZNT TE

OKDIUAFY

Right now I foel

BADT.

ANERY

BCT TVE

UNCERTAL

INVOLYED

(x) CH

COFIUENT

BLARI'

ZMIFNTIT

3 iow?

COYFTIL.

QITFT

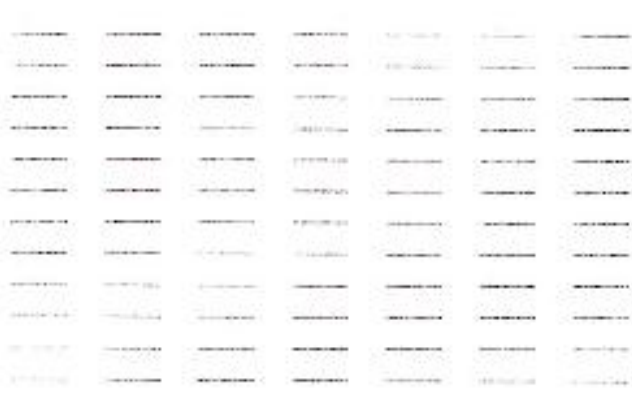

SAD

PLERSED

STILI

DEFINTTE

DERACEBD

EXCTTED

AFRATD

SIEEPY

JWFR IENDLY

FAS?

SAD

AROLISED 
Table 2. Group Members and Other Group Members' Mood and Cognition and Attendance.

\begin{tabular}{|c|c|c|c|c|}
\hline Effects & $\begin{array}{c}y \\
\text { Coefficient }\end{array}$ & $\begin{array}{c}\text { Standard } \\
\text { Error }\end{array}$ & $\begin{array}{c}t \text { test }(d f= \\
35)\end{array}$ & $\begin{array}{c}\mathrm{p} \\
\text { value }\end{array}$ \\
\hline Group Member Intercept & 1.516075 & 0.396973 & 3.819 & 0.00 \\
\hline Other Group Members Intercept & 0.076984 & 0.594200 & 0.130 & 0.00 \\
\hline Quadratic & 0.04 & 0.000454 & 9.49 & 0.000 \\
\hline Group Member Actor Depth & .015 & .036 & 0.426 & 0.672 \\
\hline Other Group Members Actor Depth & -0.307233 & 0.075323 & -4.079 & 0.000 \\
\hline Group Member Partner Depth & -0.047796 & 0.056787 & -0.842 & 0.406 \\
\hline Other Group Members Partner Depth & -0.126289 & 0.028797 & -4.385 & 0.000 \\
\hline Group Member Actor Smoothness & 0.017332 & 0.032932 & 0.526 & 0.602 \\
\hline Other Group Members Actor Smoothness & 0.305362 & 0.083534 & 3.656 & 0.001 \\
\hline Group Member Partner Smoothness & 0.017610 & 0.055085 & 0.320 & 0.751 \\
\hline Other Group Members Partner Smoothness & 0.139489 & 0.059671 & 2.338 & 0.025 \\
\hline Group Member Actor Positivity & -0.052233 & 0.022179 & -2.355 & 0.024 \\
\hline Other Group Members Actor Positivity & -0.029224 & 0.107086 & -0.273 & 0.787 \\
\hline Group Member Partner Positivity & 0.037096 & 0.058208 & 0.637 & 0.528 \\
\hline Other Group Member Partner Positivity & -0.042056 & 0.065596 & -0.641 & 0.525 \\
\hline Group Member Actor Arousal & 0.025784 & 0.022371 & 1.153 & 0.257 \\
\hline Other Group Member Actor Arousal & 0.281125 & 0.085921 & 3.272 & 0.003 \\
\hline Group Member Partner Arousal & -0.002048 & 0.052870 & -0.039 & 0.970 \\
\hline Other Group Member Partner Arousal & 0.100280 & 0.049380 & 2.031 & 0.050 \\
\hline
\end{tabular}




\section{References}

Asch, S. E. (1957). An experimental investigation of group influence. In Symposium on preventative and social psychiatry. Symposium conducted at the Walter Reed Army Institute of Research. Washington, DC: U.S. Government Printing Office.

Bloch, S., \& Reibstein, J. (1980). Perceptions by patients and therapists of therapeutic factors in group psychotherapy. British Journal of Psychiatry, 137, 274-278.

Bloch, S., Reibstein, J., Crouch, E., Holroyd, P., \& Themen, J. (1979). A method for the study of therapeutic factors in group psychotherapy. British Journal of Psychiatry, 134, 257-263.

Bonito, J., DeCamp, M., Coffman, M., \& Fleming S. (2006). Participation, Information, and Control in Small Groups: An Actor-Partner Interdependence Model. Group Dynamics: Theory, Research, and Practice, 10(1), 16-28.

Bordin, E.S. (1979). The generalizability of the psychoanalytic concept of the working alliance. Psychotherapy: Theory, Research \& Practice, 16(3), 252-260.

Brown, P. D., \& O’Leary, K. D. (2000). Therapeutic alliance: Predicting continuance and success in group treatment for spouse abuse. Journal of Consulting and Clinical Psychology, 68, 340-345.

Budman, S. H., Soldz, S., Demby, A., Feldstein, M., Springer, T., \& Davis, M. S. (1989). Cohesion, alliance, and outcome in group psychotherapy. Psychiatry, 52, 339350.

Campbell, D.T., \& Fiske, D.W. (1959). Convergent and discriminant validity by the multitrait-multimethod matrix. Psychological Bulletin, 56, 81-105.

Campbell, L., Simpson, J.A., Kashy, D.A., \& Rholes, W.S. (2001). Attachment 
orientations, dependence, and behavior in a stressful situation: An application of the actor-partner interdependence model. Journal of Social and Personal Relationships, 18(6), 821-843.

Campbell, L., \& Kashy, D.A. (2002). Estimating actor, partner, and interaction effects for dyadic data using PROC MIXED and HLM: A user-friendly guide. Personal Relationships, 9, 327 - 342.

Christiansen, K., Valbak, K., Weeke, A. (1991). Premature termination in analytic group therapy. Nordisk Psykiatrisk Tidsskrift, 45(5), 377 - 382.

Clark, R. D., III. (1990). Minority influence: The role of argument refutation on the majority position and social support from the minority position. European Journal of Social Psychology, 20, 489 - 497.

Connelly, J.L., Piper, W.E., de Carufel, F.L., \& Debbane, E.G. (1986). Premature termination in group psychotherapy: Pretherapy and early therapy predictors. International Journal of Group Psychotherapy, 36(1), 145 - 152.

Falloon, I.R. (1981). Interpersonal variables in behavioural group therapy. British Journal of Medical Psychology, 54(2). 133 - 141.

Fieldsteel, N. D., (1996). The process of termination in long-term psychoanalytic group therapy. International Journal of Group Psychotherapy, 46(1), 25 - 39.

Forsyth, D. R. (1999). Group dynamics (3rd Ed.), Belmont, CA: Wadsworth.

Frances, A., Clarkin, J., \& Perry, S. (1984). The American Journal of Psychiatry, 141(3), 406-409.

Freud, S. (1922/1959). Group psychology and the analysis of the ego (trans. James Strachey). New York: W. W. Norton. 
Friedlander, M.L., Thibodeau, J.R., \& Ward, L.G. (1985). Discriminating the 'good' from the 'bad' therapy hour: A study of dyadic interaction. Psychotherapy: Theory, Research, Practice, Training, 22(3), 631 - 642.

Hill, C. E. (2004). Helping skills: Facilitating exploration, insight, and action (2nd Ed.) Washington, DC: American Psychological Association.

Joyce, A. S., \& Piper, W. E. (1990). An examination of Mann's model of time-limited individual psychotherapy. Canadian Journal of Psychiatry, 35, 41 - 49.

Kashy, D. A., \& Kenny, D. A. (2000). The analysis of data from dyads and groups. In H. T. Reis \& C. M. Judd (Eds.), Handbook of research methods in social psychology (pp. 451 - 477). New York: Cambridge University Press.

Kelly, J. \& Moos, R. (2003). Dropout from 12-step self-help groups: Prevalence, predictors, and counteracting treatment influences. Journal of Substance Abuse Treatment, 24, $241-250$.

Kenny, D.A., \& Cook, W. (1999) Partner effects in relationship research: Conceptual issues, analytic difficulties, and illustrations. Personal Relationships, 6, 433 - 448.

Kenny, D.A., Kashy, D.A., Bolger, N. (1998). Data analysis in social psychology. In Gilbert, D.T. (Ed.), Fiske, S.T. (Ed.), \& Lindzey, G. (Ed.), The handbook of social psychology, Vols. 1 and 2. (pp. 233 - 265.) New York, NY, US: McGrawHill.

Kenny, D.A., Kashy, D.A., Manetti, L., Piero, A., \& Livi, S. (2002). The statistical analysis of data from small groups. Journal of Personality and Social Psychology, $83,126-137$. 
Kivlighan, D. M. Jr., Coleman, M. N., \& Anderson, D. C. (2000). Process, outcome and methodology in group counseling research. In S. D. Brown \& R. W. Lent (Eds.). Handbook of counseling psychology (3rd ed.). (pp. 767-796) New York: Wiley.

Kivlighan, D. M.Jr. (in press). Individual and group perceptions of therapeutic factors and session evaluation: An actor partner interdependence analysis. Group Dynamics: Theory, Research, and Practice.

Klein, R., \& Carroll, R. (1986). Patient Characteristics and Attendance Patterns in Outpatient Group Psychotherapy, International Journal of Group Psychotherapy, $36,115-132$.

Kotkov, B. (1955). The effect of individual psychotherapy on group attendance: a research study. International Journal of Group Psychotherapy, 5, 280-285.

Kotkov, B. (1958). The Effects of Individual Psychotherapy on Group Attendance. International Journal of Group Psychotherapy, 5, 280-285.

Mackenzie, K. R. (1983). The clinical application of a group climate measure. In R. R. Dies \& K. R. Mackenzie (Eds.), Advances in group psychotherapy: Integrating research and practice (pp. 159-170). Madison, CT: International Universities Press.

Mackenzie, K. R., \& Tschuschke, V. (1993). Relatedness, group work, and outcome in long-term inpatient psychotherapy groups. Journal of Psychotherapy Practice and Research, 2, 147-156.

MacNair, R., \& Corazzini, J. (1994). Client factors influencing group therapy dropout. Psychotherapy, 31(2), 352 - 362.

MacNair-Semands, R. (2002). Predicting Attendance and Expectations for Group 
Therapy. Group Dynamics: Theory, Research, and Practice, 6(3), 219 - 228.

Mallinckrodt, B. (1993). Session impact, working alliance, and treatment outcome in brief counseling. Journal of Counseling Psychology, 40(1), 25-32.

Marziali, E., Munroe-Blum, H., \& McCleary, L. (1997). The contribution of group cohesion and group alliance to the outcome of group psychotherapy. International Journal of Group Psychotherapy, 47, 475-497.

McCallum, M., Piper, W.E. (1990). A controlled study for effectiveness and patient suitability for short-term group psychotherapy. International Journal of Group Psychotherapy, 40, 431-452.

McCallum, M., Piper, W.E., \& Joyce, A.S. (1992). Dropping out from short-term group therapy. Psychotherapy: Theory, Research, Practice, Training, 29(2), 206 - 213.

McCallum, M., Piper, W. E., \& Morin, H. (1993). Affect and outcome in short-term group therapy for loss. International Journal of Group Psychotherapy, 43, 303319.

McCallum, M., Piper, W.E., Ogrodniczuk, J.S., \& Joyce, A.S. (2002). Early process and dropping out from short-term group therapy for complicated grief. Group Dynamics: Theory, Research, and Practice, 6(3), 243 - 254.

Miles, J., Paquin, J., \& Kivlighan, D.M. Jr. (2009). What's group got to do with it: An actor partner interdependent analysis of intimate behaviors in groups. Manuscript submitted for publication.

Moscovici, S., Mucchi-Faina, A., \& Maass A. (Eds.). (1994). Minority Influence. Chicago: Nelson-Hall.

Murray, S.L., Holmes, J.G., \& Griffin, D.W. (1996). The self-fulfilling nature of positive 
illusions in romantic relationships: Love is not blind, but prescient. Journal of Personality and Social Psychology, 71(6), 1155 - 1180.

Nemeth, C. J., \& Wachtler, J. (1974). Creating the perceptions of consistency and confidence: A necessary condition for minority influence. European Journal of Social Psychology, 13, 45 - 55.

Newcomb, T. M. (1943). Personality and social change. New York: Dryden.

Ogrodniczuk, J. S., Piper, W. E., \& Joyce, A.S. (2006). Treatment compliance among patients with personality disorders receiving group psychotherapy: What are the roles of interpersonal distress and cohesion? Psychiatry, 69(3), 249 - 261.

Osgood, C. E., May, W., Miron, M. (1957). The measurement of meaning. Urbana, IL: University of Illinois Press.

Otten, R.; van der Zwaluw, C.S., van der Vorst, H., \& Engels, R.C.M.E.(2008). Partner effects and bidirectional parent-child effects in family alcohol use. European Addiction Research, 14(2), 106 - 112.

Piper, W. E., Jones, B. D., Lacroix, R., Marrache, M., \& Richardsen, A. M. (1984). Pregroup interactions and bonding in small groups. Small Group Behavior, $15,51-62$.

Piper, W.E., Ogrodniczuk, J.S., \& Joyce, A.S., McCallum, M., Rosie, J.S., O'Kelly, J.G., \& Steinberg, P.I. (1999). Prediction of dropping out in time-limited, interpretive individual psychotherapy. Psychotherapy: Theory, Research, Practice, Training, 36(2), 114-122.

Piper, W. E., Marrache, M., Lacroix, R., Richardsen, A. M., \& Jones, B. D. (1983). Cohesion as a basic bond in groups. Human Relations, 36, 93-108. 
Popp, D., Laursen, B., Kerr, M., Stattin, H., \& Burk, W.K. (2008). Modeling homophily over time with and actor-partner interdependence analysis. Developmental Psychology, 44(4), 1028-1039.

Raudenbush, S., Bryk, A., \& Congdon, R. (2005). Hierarchical linear and nonlinear modeling (Version 6.02) [Computer software]. Chicago: Scientific Software International.

Reynolds, S., Stiles, W. B., Barkham, M., Shapiro, D. A., Hardy, G. E., \& Rees, A. (1996). Acceleration of changes in session impact during contrasting time-limited psychotherapies. Journal of Consulting and Clinical Psychology, 64, 577-586.

Roback, H.B., \& Smith, M. (1987). Patient attrition in dynamically oriented treatment groups. The American Journal of Psychiatry, 144(4), 426-431.

Robins, R.W., Caspi, A., \& Moffitt, T.E., (2000). Two personalities, one relationship: Both partners' personality traits shape the quality of their relationship. Journal of Personality and Social Psychology, 79(2), 251 - 259.

Rosenzweig, S., \& Folman, R. (1974). Patient and therapist variable affecting premature termination in group psychotherapy. Psychotherapy: Theory, Research and Practice, 11, 76-79.

Russell, J.A. (1978). Evidence of convergence validity on dimensions of affect. Journal of Personality and Social Psychology, 36, $176-185$.

Russell, J.A. (1979). Affective space is bipolar. Journal of Personality and Social Psychology, 37, $345-356$.

Schachter, S. (1959). The psychology of affiliation. Stanford, CA: Stanford University Press. 
Segrin, C., Badger, T.A., Meek, P., Lopez, A.M., Bonham, E., \& Sieger, A. (2005).

Dyadic interdependence on affect and quality-of-life trajectories among women with breast cancer and their partners. Journal of Social and Personal Relationships, 22(5), 673 - 689.

Sharry, J., \& Owens, C. (2000) 'The rules of engagement': A case study of a group with 'angry' adolescents. Clinical Child Psychology and Psychiatry, 5(1), 53-62.

Sherif, M. (1936). The psychology of social norms. New York: Harper \& Row.

Shoukri, M.M., Edge, V.L. (1996). Statistical methods for health sciences. Boca Raton: RC Press.

Singer, E. (1990). Reference groups and social evaluation. In M. Rosenberg \& R.H. Turner (Eds.), Social psychology: Sociological perspectives (pp. 66-93). New Brunswick, NJ: Transaction Publishers.

Stiles, W.B. (1980). Measurement of the Impact of psychotherapy sessions. Journal of Counseling and Clinical Psychology, 48, 176 - 185.

Stiles, W. B., Gordon, L. E., \& Lani, J. A. (2002). Session evaluation and the Session Evaluation Questionnaire. In G. S. Tryon (Ed.), Counseling based on process research: Applying what we know (pp. 325-343). Boston, MA: Allyn \& Bacon.

Stiles, W.B., Reynolds, S., Hardy, G.E., Rees, A., Barkham, M., \& Shapiro, D.A. (1994). Evaluation and description of psychotherapy sessions by clients using the session evaluation questionnaire and the sessions impact scale. Journal of Counseling Psychology, 41(2), 175 - 185.

Stiles, W.B., Shapiro, D.A., \& Firth-Cozens, J.A. (1988). Do sessions of different 
treatments have different impacts? Journal of Counseling Psychology, 35(4), 391396.

Stiles, W.B., Shapiro, D.A., \& Firth-Cozens, J.A. (1990). Correlations of session evaluations with treatment outcome. British Journal of Clinical Psychology, 29(1), 13-21.

Stiles, W.B., \& Snow, J.S. (1984). Counseling session impact as viewed by novice counselors and their clients. British Journal of Clinical Psychology, 29, 13 - 21.

Stone, W., Blaze, M., \& Buzzuto, J. (1980). Late dropouts from group psychotherapy. American Journal of Psychotherapy, 34(3), 401-413.

Stone, W., \& Rutan, S. (1984). Duration of treatment in group psychotherapy. International Journal of Group Psychotherapy, 34(1), 93-109.

Tasca, G., Ramsay, T., Corace, K., Illing, V., Bone, M., Bissada, H., \& Balfour, L. (2010). Modeling longitudinal data from a rolling therapy group program with membership turnover: Does group culture affect individual alliance? Group Dynamics: Theory, Research, and Practice, 14(2), 151-162.

Tryon, G.S. (1990). Session depth and smoothness in relation to the concept of engagement in counseling. Journal of Counseling Psychology, 37(3), 248 - 253.

Weiner, M. (1984). Outcome of psychoanalytically oriented group therapy. Group, 8, 3-12.

Witte, E. H. (1994). Minority influences and innovations: The search for an integrated explanation of psychological and sociological models. In S. Moscovici, A.

Mucchi-Faina, \& A. Maass (eds.), Minority Influence (pp. 67-93). Chicago: Nelson-Hall. Yalom, I. (1995). The theory and practice of group psychotherapy $\left(4^{\text {th }}\right.$ Ed.). New York, 
NY: Basic Books, Inc.

Yalom, I. (1966). A study of group therapy dropouts. Archives of General Psychiatry, $14,393-414$.

Yalom, I., Houts, P.S., \& Zimerberg, S.M. (1967). Prediction of improvement in group therapy: An exploratory study. Archives of General Psychiatry, 17(2), 159 168.

Yalom, I. and Leszcz, D., (2005). The theory and practice of group psychotherapy (5th ed.). New York, NY: Basic Books, Inc.

Yalom, I., Tinklenberg, J.,\& Gilula, M. (1968). Curative factors in group therapy. Unpublished manuscript.

Yuksel, S., Kulaksizoglu, I., Turksoy, N., \& Sahin, D. (2000). Group psychotherapy with female-to-male transsexuals in Turkey. Archives of Sexual Behavior, 29(3), 279290. 